\title{
Wind Measurements From an Array of Oceanographic Moorings and From F/S Meteor During JASIN 1978
}

\author{
Robert A. Weller and Richard E. Payne \\ Woods Hole Oceanographic Institution
}

W. G. LARGE

National Center for Atmospheric Research

WALTER ZENK

Institut für Meereskunde an der Universität Kiel

\begin{abstract}
During the Joint Air-Sea Interaction (JASIN) experiment conducted in the northern Rockall Trough in the summer of 1978, oceanographic moorings with surface buoys carrying wind recorders were deployed in an array designed to investigate the variability of the near-surface wind field at scales of from 2 to $200 \mathrm{~km}$. The wind records together with observations taken on board the research vessels participating in JASIN have provided ground truth measurements for the sea surface wind velocity sensors on the Seasat satellite. During most of the experiment the wind field was characterized by spatial scales large in comparison with the separations between the buoys. On several occasions, spatial differences associated with cold fronts were identified, and it was possible to track the passage of the front through the array. However, quantitative analysis of the variability of the wind field was complicated both by a lack of data due to mechanical failures of some instruments and by significant differences in the performance of the diverse types of wind recorders. Reevaluation of the instruments used in JASIN and recent comparison of some of these instruments with more conventional sets of wind sensors confirm the possibility that there is significant error in the JASIN wind measurements made from the buoys. In particular, the vector-averaging wind recorder on W2, which was one of the few instruments to recover a full length record and which was chosen during a Seasat-JASIN workshop as the JASIN standard, had performance characteristics that were among the most difficult to explain.
\end{abstract}

\section{INTRODUCTION}

The Joint Air-Sea Interaction (JASIN) experiment conducted in the summer of 1978 (JASIN 1978) was an international project first proposed by the Royal Meteorological Society to the Royal Society of the United Kingdom in 1966. The many participants were involved in investigating many different facets of air-sea interaction (for an overview of the scientific and operational plans of JASIN 1978, see Pollard [1978]). One specific goal of the oceanographic program was to investigate the horizontal variability of the surface wind field on scales of 2 to $200 \mathrm{~km}$, with the hope that the variability in the wind stress field could be related to horizontal variability of the near-surface oceanic velocity and temperature fields. In order to do this, self-recording anemometers or wind recorders were mounted on buoys that were moored in a fixed array. The buoys proved to be difficult platforms from which to make wind measurements. Salt spray and waves and the pitch, roll, and heave of the buoys created the potential for corrosion, wear, breakage, and error. However, because surface floats cause less flow disturbance than ships, the buoy wind records were considered to be the best data set for analysis of the variability of the surface wind field and an important part of the ground truth data to be compared with the data from the Seasat A scatterometer.

This paper provides an overview of the instrumentation deployed on the JASIN oceanographic buoys (section 2) and

Copyright 1983 by the American Geophysical Union.

Paper number $3 \mathrm{C} 1113$.

0148-0227/83/003C-1113\$05.00 of the wind data collected during the experiment (section 3). Typically, the wind field was dominated by flow with scales large in comparison with the separation of the buoys, but it was possible on occasion to identify a shift in wind direction that progressed through the array. Further quantitative analysis of the variability of the wind data was attempted (section 4), and as a further aid to interpretation, carefully selected wind data from Gill propeller-vane anemometers mounted on F/S Meteor during JASIN were included in the intercomparisons. Because of the disparate performance of the instruments used in JASIN, it was difficult to distinguish instantaneous differences in wind velocity associated with the spatial variability of the wind from instantaneous differences associated with different instrument types. The area of the JASIN experiment, as will be discussed, was characterized by weather systems with scales large in comparison with the moored array, and these weather systems moved slowly through the area. As a result the levels of horizontal variability were, at low frequencies, small, and comparisons of averaged and mean wind velocities are used to investigate differences in anemometer performance. Significant differences in mean winds were found, so we reevaluated the ability of the instruments used in JASIN to make accurate wind measurements (section 5). The literature on anemometer performance was surveyed, wind tunnel tests were conducted, and an intercomparison experiment carried out on a pier. Discussion of the JASIN data in light of the reevaluation is presented (section 6), as are conclusions about the appropriateness of using data from the buoys to calibrate the Seasat sensors. The concern in this paper is that the limitations of the anemometers be understood; Pierson [1983] addresses the problem of intercomparing ship, buoy, 


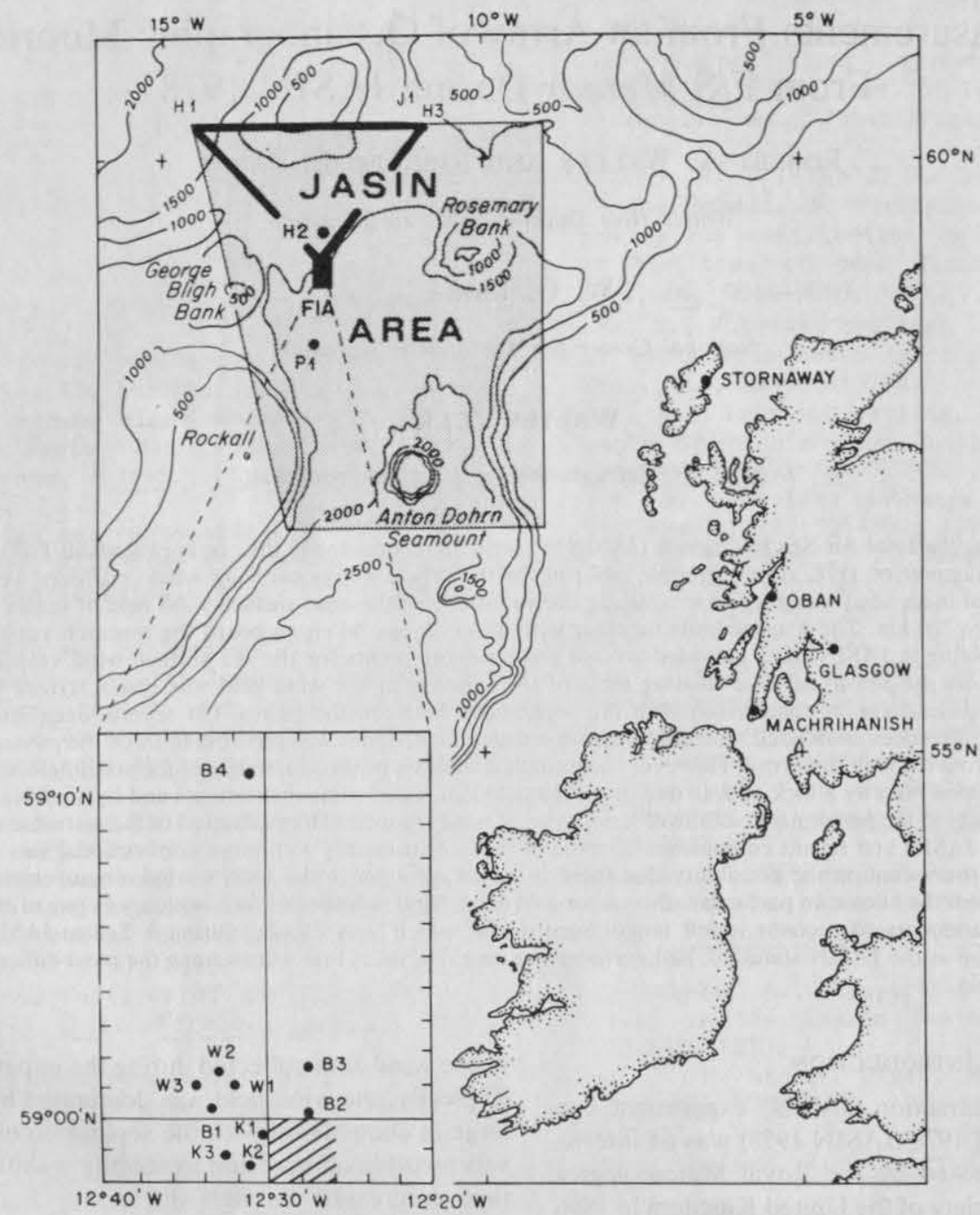

Fig. 1. The locations of the meteorological triangle (heavy lines) and of the moorings deployed during JASIN 1978. The inset shows the area known as the fixed intensive array (FIA) and the area (shaded) in which F/S Meteor operated.

and satellite winds which are each based on different spatial and temporal averages.

\section{The ARRAy and the Wind Recorders}

The JASIN 1978 experiment was conducted in the northern Rockall Trough, to the northwest of Scotland (Figure 1). The earliest deployment of a mooring was on July 9, and the last mooring was recovered on September 8 . Moorings $\mathrm{H} 1$ and $\mathrm{H} 3$ were located at $60^{\circ} 10^{\prime} \mathrm{N}$ at the northern corners of the JASIN meteorological triangle with $\mathrm{J} 1$ close to $\mathrm{H} 3$. Most moorings were clustered around the southern corner of this triangle in the fixed intensive array (FIA) of oceanographic moorings. P1 was $44 \mathrm{~km}$ to the south of the FIA. Moorings W2, B1, B2, B3, B4, K2, K3, H1, H2, H3, P1, and J1 had wind recorders. $\mathrm{H} 1, \mathrm{H} 3$, and $\mathrm{P} 1$ returned no data. The tape recorder in the instrument on $\mathrm{J} 1$ failed. Partial or full length records were available from $\mathrm{W} 2, \mathrm{H} 2, \mathrm{~B} 1, \mathrm{~B} 2, \mathrm{~B} 3, \mathrm{~B} 4, \mathrm{~K} 2$, and $\mathrm{K} 3$ and from F/S Meteor. While on station, F/S Meteor drifted to the southeast of the FIA. Table 1 summarizes the data used in this discussion.

The wind recorders were mounted on the surface buoys in a fashion that minimized flow disturbance. In some installations, such as on W2 (Figure 2a), large fins were attached to the superstructure of the buoys in a successful attempt to orient the buoys with respect to the wind and prevent blockage of the flow to the wind recorders. In other installations, such as K2 (Figure $2 b$ ) and K3 (Figure 2c), fins were not used. Flow distortion by the Meteor was minimized by using wind data from two different locations depending on the relative direction of the wind. For winds over the bow $\pm 60^{\circ}$ a Gill propeller-vane anemometer (GPVA) above the bridge of the ship at $22 \mathrm{~m}$ was used, while for winds from either port or starboard $\left(70^{\circ}\right.$ to $120^{\circ}$ relative to the bow) a GPVA at 9-m elevation on a boom extending $10 \mathrm{~m}$ ahead of the bow was used [Large and Pond, 1982].

The wind recorders used on the buoys were not standard commercial meteorological units because previous installations of meteorological sensors on oceanographic buoys had demonstrated the need for extremely rugged equipment. Salt spray hit the sensors, leaving behind salt in the bearings and on all other surfaces. The toroidal buoys heave, pitch, and roll at surface wave frequencies $(0.04-0.5 \mathrm{~Hz})$, so that the wind recorders experience large forces under alternating acceleration and deceleration. (Welds in the aluminum construction of the vector-measuring wind recorders (VMWR's) eventually parted under this continual working.) The wind recorders must also be self-contained, with internal compasses, recorders, and batteries. Because of the severe 
TABLE 1. JASIN Wind Records

\begin{tabular}{|c|c|c|c|c|c|c|}
\hline Platform & Instrument & Investigator & $\begin{array}{l}\text { Sampling } \\
\text { Rate, min }\end{array}$ & $\begin{array}{l}\text { Platform } \\
\text { Type }\end{array}$ & Height, m & Span of Record \\
\hline W2 & $\begin{array}{l}\text { vector-averaging } \\
\text { wind recorder }\end{array}$ & Payne (WHOI) & 15 & toroid buoy & 3.5 & July $30-$ Sept. 6 \\
\hline W2 & $\begin{array}{l}\text { vector-measuring } \\
\text { wind recorder }\end{array}$ & Davis (SIO) & 2 & toroid & 3.5 & July 30 -Aug. 17 \\
\hline $\mathrm{H} 2$ & $\begin{array}{l}\text { vector-measuring } \\
\text { wind recorder }\end{array}$ & Davis (SIO) & 2 & toroid & 3.5 & $\begin{array}{l}\text { July } 16-\text { Aug. } 10 \\
\text { Aug. } 27-S e p t .2\end{array}$ \\
\hline B1 & Aanderaa wind & Paulson (OSU) & 3.5 & toroid & 2.5 & Aug. 1 -Sept. 6 \\
\hline $\begin{array}{l}\mathrm{B} 2 \\
\mathrm{~B} 3\end{array}$ & recorder & & & & & July $29-$ Sept. 6 \\
\hline B4 & & & & & & $\begin{array}{l}\text { July } 28 \text {-Sept. } 6 \\
\text { July } 28-S e p t .4\end{array}$ \\
\hline $\mathrm{K} 2$ & Aanderaa wind & Käse (IfM) & 10 & toroid & 7.7 & Aug. 22-Sept. 4 \\
\hline K3 & recorder & Zenk (IfM) & & cone & 2 & Aug. 22-Sept. 7 \\
\hline Meteor & $\begin{array}{l}\text { Gill propeller-vane } \\
\text { anemometer }\end{array}$ & Large (UBC) & 2 & ship & $\begin{array}{c}22 \text { or } \\
9\end{array}$ & $\begin{array}{l}\text { July } 23-\text { Aug. } 9 \\
\text { Aug. } 21-\text { Sept. } 5\end{array}$ \\
\hline
\end{tabular}

WHOI, Woods Hole Oceanographic Institution, Woods Hole, Massachusetts; SIO. Scripps Institution of Oceanography, La Jolla, California; OSU, Oregon State University, Corvallis, Oregon; IfM, Institut für Meereskunde an der Universität Kiel, Kiel. Federal Republic of Germany; UBC, University of British Columbia, Vancouver, British Columbia, Canada.

environment and the need for a low-power self-contained package, the three types of wind recorders used on the $\mathrm{H}$, $\mathrm{W}, \mathrm{B}$, and $\mathrm{K}$ moorings were derivatives of oceanographic current meters. The instruments used on the buoys were the vector-averaging wind recorder (VAWR), the vector-measuring wind recorder (VMWR), and the Aanderaa wind recorder (AWR). The VAWR was used on th W2 buoy. VMWR's were used on the W2 and H2 buoys. The B and $\mathrm{K}$ buoys were equipped with AWR's. The sensors used on these instruments are shown in Figure 3.

The VAWR is based on the vector-averaging current meter (VACM) manufactured by EG\&G Sea-Link, which is

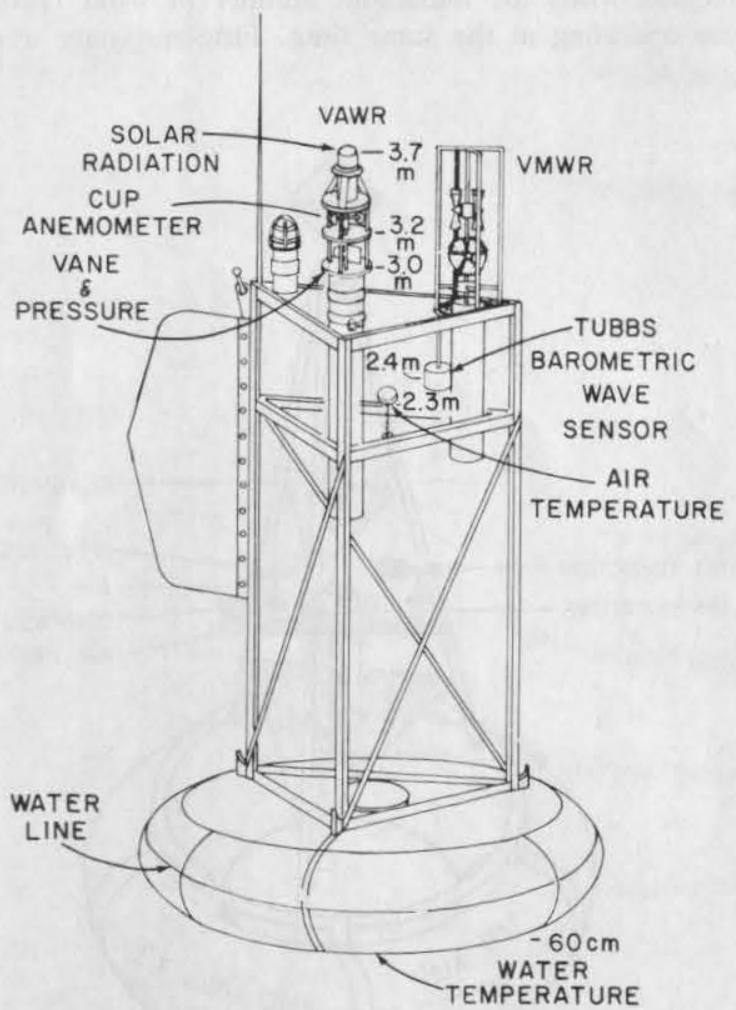

Fig. $2 a$. The W2 surface buoy with the vector-averaging wind recorder (VAWR) and vector-measuring wind recorder (VMWR). The fin orients the buoy with respect to the wind so that neither wind recorder blocks the flow to the other. an internally recording oceanographic current meter with internal mechanical compass and vector-averaging electronics. The original sensors were replaced by a set of three cups manufactured by Teledyne Geotech and a balanced vane enclosed in a protective cage [Payne, 1974]. With each rotation of the cups, the compass and vane bearings were summed to give direction relative to magnetic north, and the sine and cosine of this angle were summed in two storage registers. At the end of a sample interval the contents of these storage registers, vector-averaged components of the wind velocity, were written to magnetic tape. Both cup and vane are sandwiched between solid aluminum discs that form part of the protective cage. The cup assembly has a distance constant of about $15 \mathrm{~m}$ [Payne, 1981]. With fairly crude but rugged bearings and low revolution rate because of relatively long $(8.5 \mathrm{~cm})$ cup arms, the cup sensor is reliable for long deployments at sea but has a high threshold, of the order of $1 \mathrm{~m} \mathrm{~s}^{-1}$.

The VMWR is an adaptation of the vector-measuring current meter (VMCM [Weller and Davis, 1980]). Dual orthogonal propellers sense the horizontal velocity vector. For each quarter revolution of either propeller the instrument heading is determined by an internal flux gate compass designed to tolerate tilts of $\pm 15^{\circ}$. Cosines and sines of that angle are added to storage registers, so that the VMWR, like the VAWR described above, computes and records vectoraveraged wind velocities. The VMCM propellers have an angular response that is very close to cosine; over $360^{\circ}$ the rms deviation of the response from cosine is approximately $1.5 \%$ of the maximum response. The blades of the propellers on the VMWR were made thinner than those on the VMCM and are $0.1588 \mathrm{~cm}(0.0625$ in.) thick and made of Lexan polycarbonate plastic. On W2 the orthogonal propellers were fixed so that the axes of both formed a $45^{\circ}$ angle with the fin. The propeller sensors have an on-axis distance constant of $11 \mathrm{~m}$ [Payne, 1981] and a threshold of approximately $0.3 \mathrm{~m} \mathrm{~s}^{-1}$. For winds parallel to the fin on $\mathrm{W} 2$, the distance constant is probably longer, perhaps by $10 \%$. The VMWR had not been used in a field experiment prior to JASIN, and its deployment was, in part, a performance and endurance test.

The Aanderaa wind record (AWR) is a commercially available adaptation of the Aanderaa Savonius rotor and 

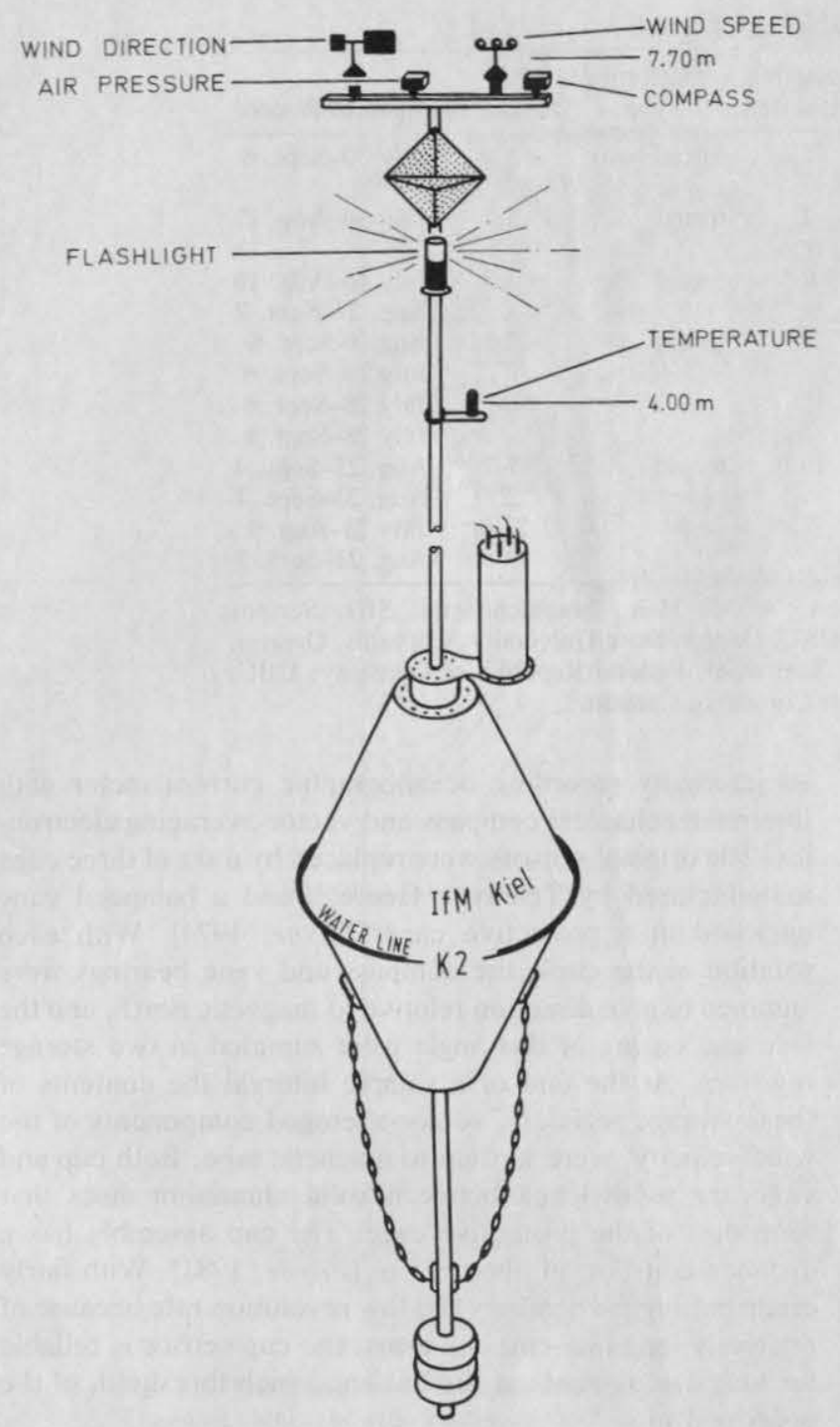

Fig. $2 b$. The $\mathrm{K} 2$ surface buoy with an Aanderaa wind recorder (AWR).

vane current meter. A set of cups and a vane, separate from the data logger package, sense speed and direction. Total turns of the cup (scalar-averaged speed) and instantaneous wind direction are recorded at the end of each data sampling interval; the AWR is not a vector-averaging recorder. The manufacturers of the instrument (Aanderaa) report distance constants of 5 and $4 \mathrm{~m}$, respectively, for the cup sensors and the vane.

The Gill propeller-vane anemometer (GPVA) consists of a vane-mounted helicoidal propeller with a horizontal axis and an optional helicoidal propeller with its axis tilted down $60^{\circ}$ and mounted off the vertical shaft that supports the vane. A detailed description of the system used on F/S Meteor is given by Pond et al. [1979]. The calibration of the propellers is set by their pitch. They have demonstrated both good calibration stability and, at wind speeds above about $1 \mathrm{~m}$ $\mathrm{s}^{-1}$, outstanding linearity of calibration [Gill, 1975]. Speed and direction were low pass filtered (single-pole R-C circuits with 25 -s time constants) and recorded every $2 \mathrm{~min}$. On F/S Meteor the system did not include a compass, so only wind directions relative to the ship were available. Crude absolute wind directions were calculated using hourly logged ship's heading while the ship was on station near the buoys (Figure 1). An advantage of shipboard operation was that sensors could be serviced frequently and propellers, bearings, and generators replaced. (Detailed descriptions of the operations on F/S Meteor can be found in the work of Siedler and Zenk [1980].)

\section{Gross Characteristics of the Wind Field OBSERVED DURING JASIN 1978}

Details of the meteorological (and oceanographic) conditions during JASIN 1978 and of the analyses of the data that followed the experiment have been reported elsewhere (see. for example, Pollard et al. [1983], Guymer et al. [1983], and other papers in that same volume). Relevant to this discussion are the daily weather maps produced by the British Meteorological Office [Royal Society, 1979] and the maps of surface wind produced by the Seasat A scatterometer [Woiceshyn et al., 1980]; these maps show that conditions during the JASIN experiment were dominated by large (in comparison with the scale of the wind recorder array) weather systems that moved slowly through the JASIN area. As a result, average winds at all the buoys were usually similar in magnitude and direction. Stick plots of 4-hour-averaged wind velocity vectors from the instruments on the buoys (Figure 4) show an overall uniformity and generally agree with surface winds deduced from the daily weather maps and the satellite maps.

On several occasions, careful examination of the stick plots showed a departure from spatial uniformity, veering of the wind direction at one end of the array that lagged that at the other end by several hours. On August 30 there was such an event, which is presented as an example of the data collected when the maximum number of wind recorders were operating at the same time. Fifteen-minute average

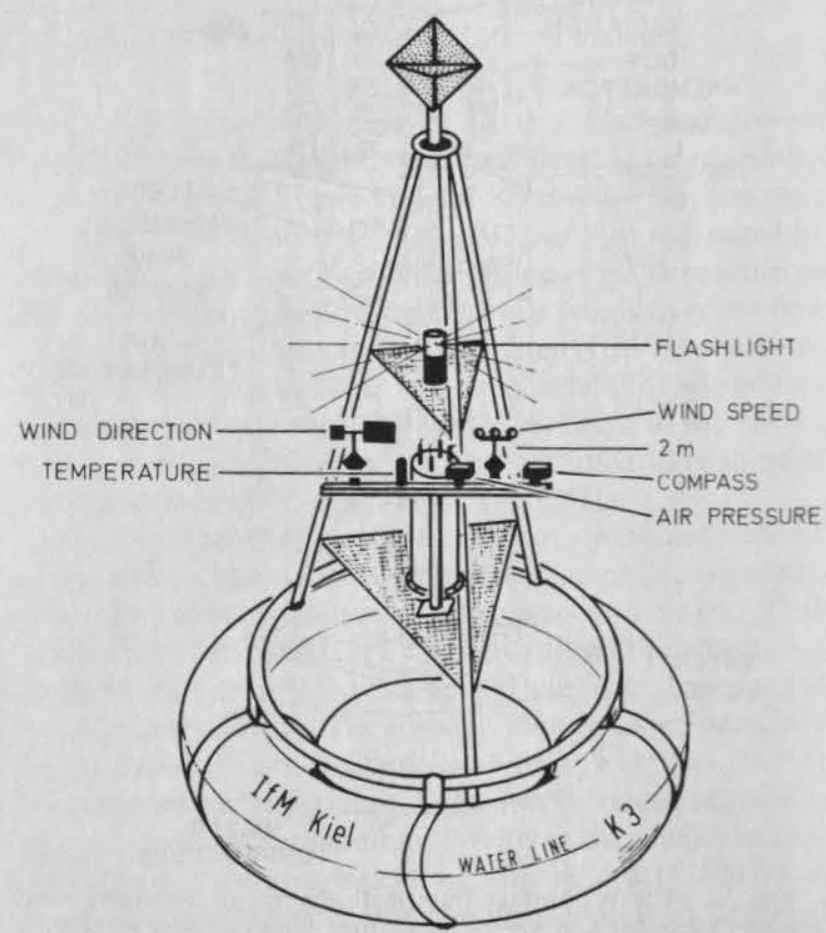

Fig. $2 c$. The K3 surface buoy with an Aanderaa wind recorder (AWR). 

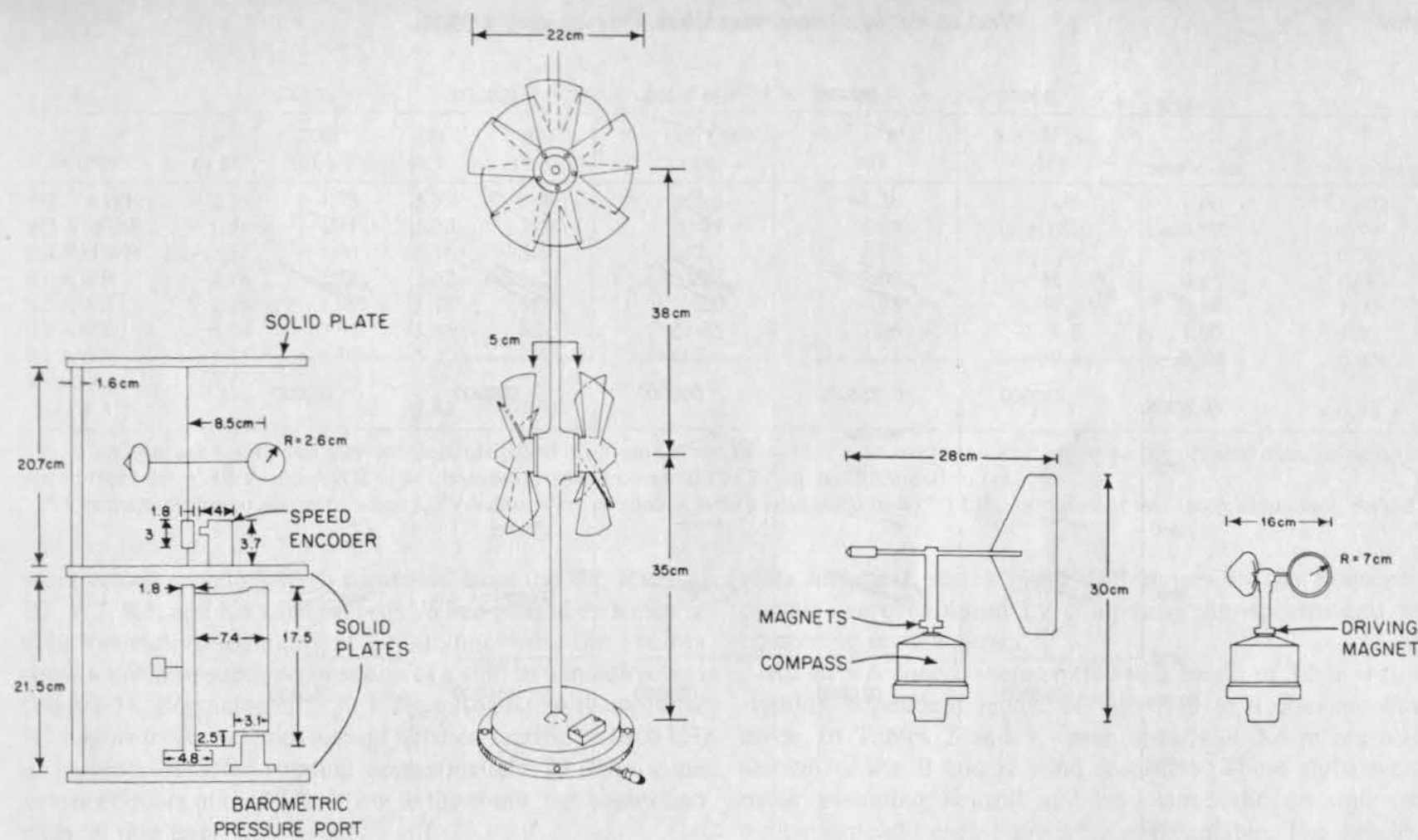

Fig. 3. The sensors used on (left) the VAWR, (middle) the VMWR, and (right) the AWR are shown drawn to the same scale, with important dimensions indicated. The vanes on the K2 AWR and K3 AWR were of slightly different shape, as shown in Figures $2 b$ and $2 c$.

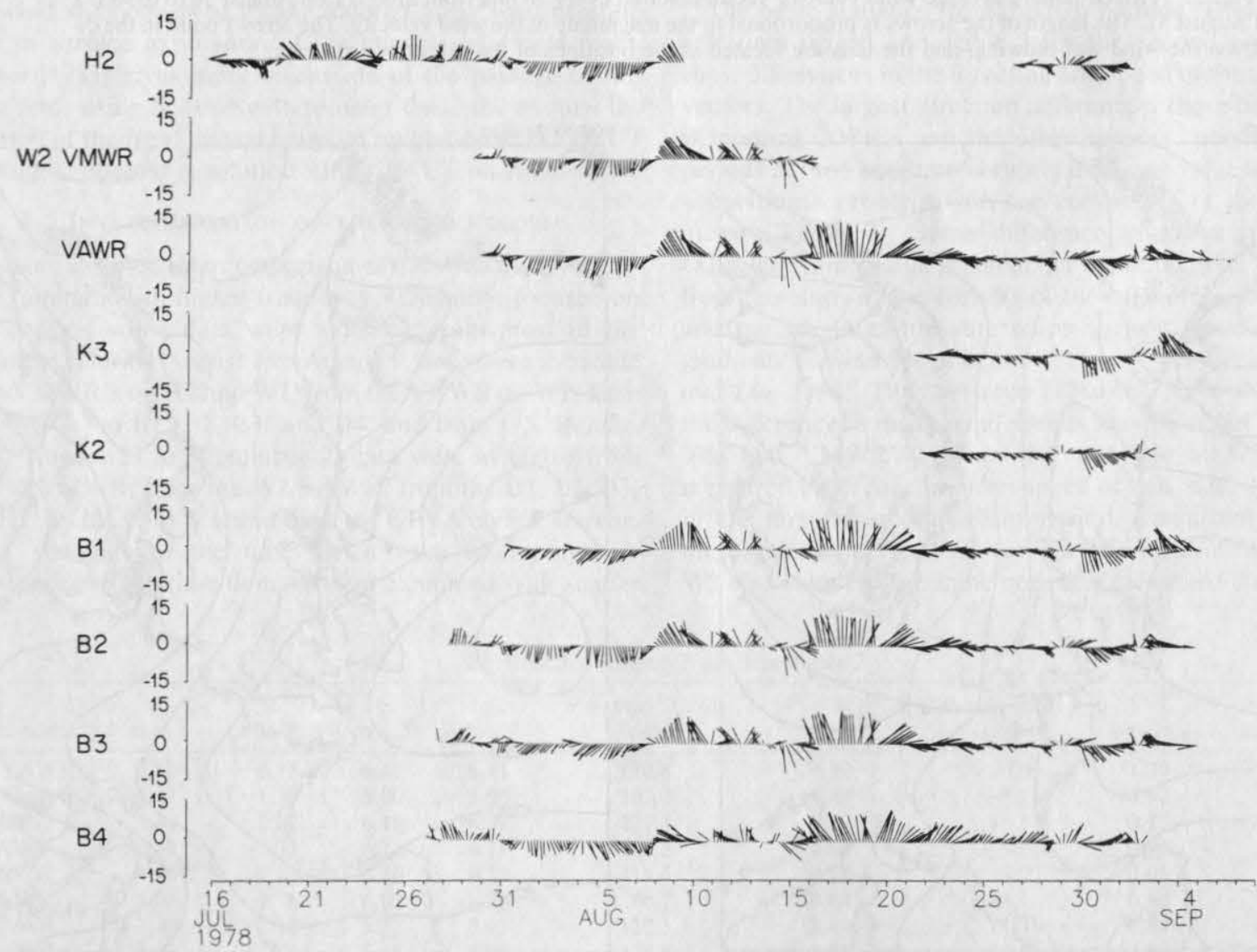

Fig. 4. Stick plots of 4-hour-averaged wind velocities from the wind recorders on $\mathrm{H} 2$, W2, the $\mathrm{K}$ moorings, and the B moorings. A stick pointing toward the top of the plot indicates wind toward the north; a stick pointing to the right indicates wind toward the east. The magnitude of the wind vector in meters per second is represented by the length of the stick as indicated by the vertical scale. 


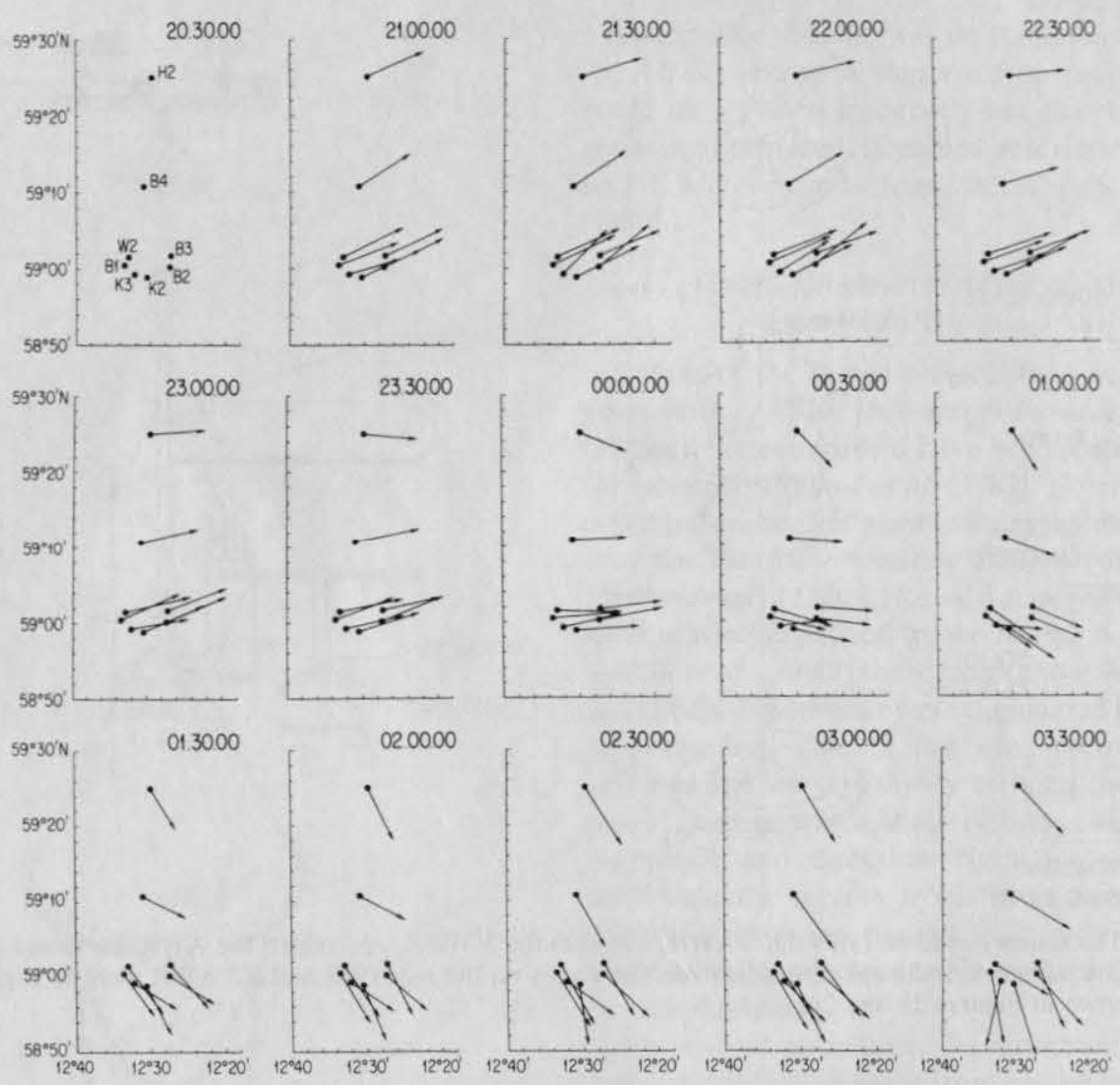

Fig. 5. Fifteen-minute average wind velocity vectors plotted every $30 \mathrm{~min}$ from $2100 \mathrm{UT}$ on August 30 to $0330 \mathrm{UT}$ on August 31. The length of the arrows is proportional to the magnitude of the wind velocity. The arrows point in the direction the wind was blowing, and the tails are located at the positions of the respective moorings.
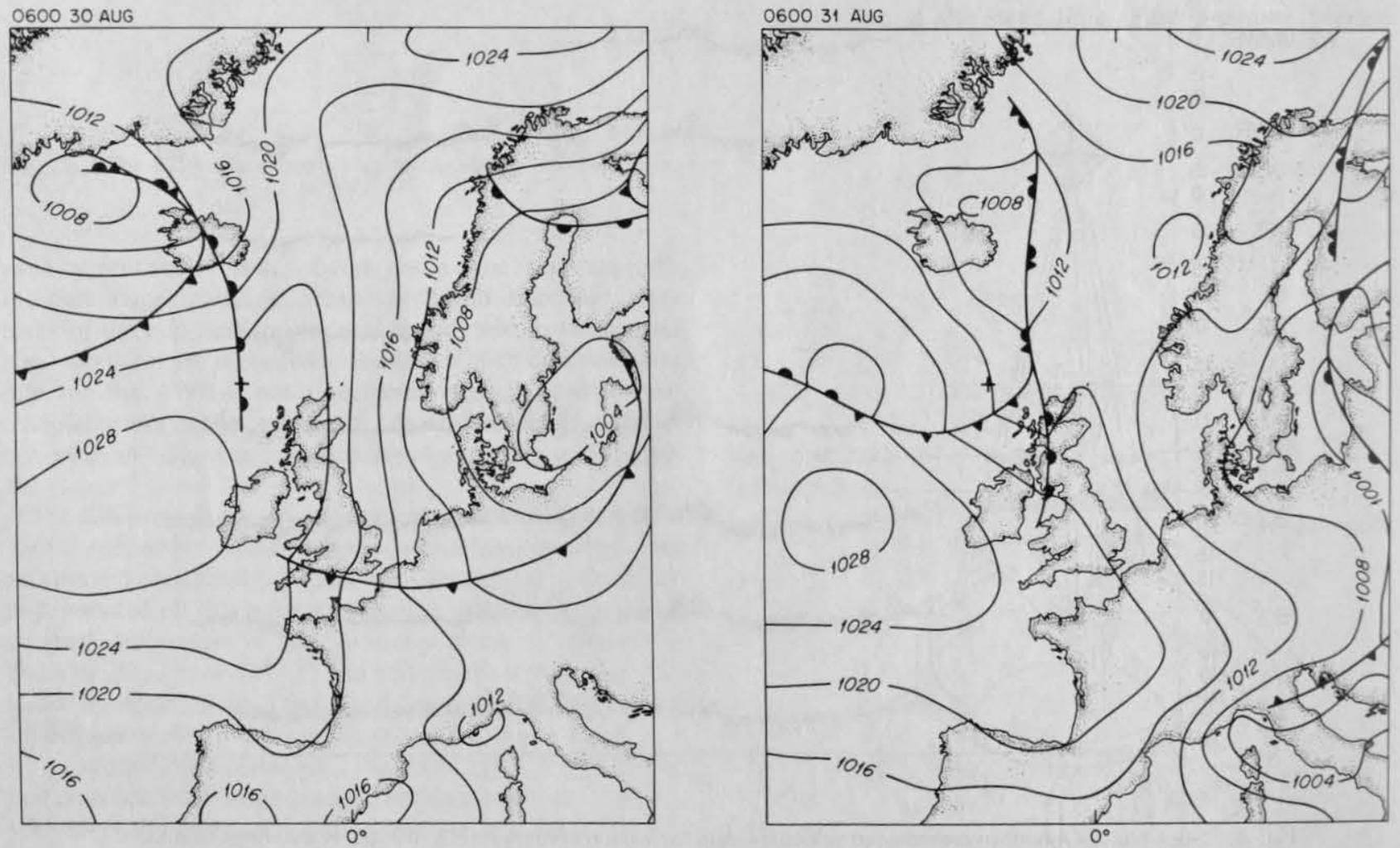

Fig. 6. Surface analyses for 0600 UT on August 30 and 0600 UT on August 31 . The site of the JASIN experiment, northwest of Scotland, is marked by a cross. These figures are based on maps produced by the British Meteorological Office. 
TABLE 2. August 1 to August 9

\begin{tabular}{|c|c|c|c|c|c|c|c|c|c|}
\hline Sensor & $\mathrm{m} \mathrm{s}^{-1}$ & $\mathrm{~m} \mathrm{~s}^{-1}$ & $\mathrm{~m} \mathrm{~s}^{-1}$ & $\begin{array}{l}\bar{s}_{3.5 \cdot} \\
\mathrm{m} \mathrm{s}^{-1}\end{array}$ & $\begin{array}{c}\theta=\tan ^{-1}(\bar{v} / \bar{u}), \\
\operatorname{deg}\end{array}$ & $\begin{array}{c}\left(\bar{u}^{2}+\bar{v}^{2}\right)^{1 / 2} \\
\mathrm{~m} \mathrm{~s}\end{array}$ & $\begin{array}{c}\theta-\theta_{\text {VAWR }} \\
\text { deg }\end{array}$ & $\bar{s} / \tilde{s}_{\mathrm{VAWR}}$ & $\bar{s}_{3.5} / \tilde{S}_{3.5 \mathrm{VAWR}}$ \\
\hline W2 VAWR & -2.26 & -4.78 & 5.89 & 5.89 & 205.3 & 5.28 & 0.0 & 1.00 & 1.00 \\
\hline W2 VMWR & -1.93 & -4.31 & 5.26 & 5.26 & 204.1 & 4.72 & -1.2 & 0.89 & 0.89 \\
\hline H2 VMWR & -2.57 & -4.00 & 5.16 & 5.16 & 212.7 & 4.75 & 7.4 & 0.90 & 0.90 \\
\hline B1 AWR & -4.18 & -2.78 & 5.62 & 5.79 & 236.4 & 5.02 & 31.1 & 0.95 & 0.98 \\
\hline B2 AWR & -1.09 & -4.86 & 5.78 & 5.96 & 192.6 & 4.98 & -12.7 & 0.94 & 1.01 \\
\hline B3 AWR & -4.34 & -2.98 & 5.85 & 6.03 & 214.5 & 5.26 & 9.2 & 1.00 & 1.02 \\
\hline B4 AWR & 1.15 & -4.57 & 5.42 & 5.58 & 165.9 & 4.71 & -39.4 & 0.89 & 0.95 \\
\hline \multicolumn{10}{|l|}{ Meteor } \\
\hline GPVA* & & & 5.61 & 5.61 & & & & 0.93 & 0.93 \\
\hline
\end{tabular}

$u, v$ are average vector velocity components based on $15-\min$ series of $(u, v) ; s$ is an average speed based on the original data, using rotor speed from the VAWR and AWR's; $\bar{s}_{3.5}$ is average speed corrected to $3.5 \mathrm{~m}$, as discussed in text.

* Comparison based on times when GPVA data were available, which amounted to $83 \%$ of the duration of this intercomparison period.

wind velocity vectors were computed from the $\mathrm{H} 2, \mathrm{~B} 1, \mathrm{~B} 2$, $\mathrm{B} 3$, W2, K2, and K3 wind records. When plotted on a map at their respective locations at $\frac{1}{2}$-hour intervals, the vectors show a north to south progression of a shift in wind direction (Figure 5). Beginning at 2230 UT on August 30 the wind at $\mathrm{H} 2$ begins to veer clockwise and finishes veering by $0100 \mathrm{UT}$ on August 31 after rotating approximately $70^{\circ}$; the same veering occurs at the FIA, $40 \mathrm{~km}$ to the south, but begins and ends $90 \mathrm{~min}$ later.

Time series of barometric pressure, air temperature, wind speed, and wind direction from the W2 VAWR show that a drop in barometric pressure and air temperature accompanied the wind shift at W2. Surface analyses (Figure 6) for 0600 UT on August 30 and 0600 UT on August 31 show that the wind shift observed by the moored array was, presumably, a surface expression of the passage of a cold front. Brown [1983] gives more discussion of the passage of this front and, using Seasat scatterometer data, shows how the location of the front moved between revolution 929 (2300 UT on August 30) and revolution 930 (0100 UT on August 31).

\section{INTERCOMPARISON OF THE WIND RECORDS}

A more detailed intercomparison of the wind data, including examination of higher-frequency variability, focused on two periods when data were available from most of the platforms. During August 1 to August 9, data were available from VMWR's on $\mathrm{H} 2$ and W2, from the VAWR on W2, from the AWR's on B1, B2, B3, and B4, and from F/S Meteor. From August 27 to September 2, data were available from the H2 VMWR, from the W2 VAWR, from the B1, B2, B3, $\mathrm{B} 4, \mathrm{~K} 2$, and K3 AWR's, and from the GPVA on F/S Meteor. Basic statistics of the time series were intercompared. Differences in the time domain were examined with scatter plots and time series plots. Differences in the frequency domain were explored by comparing autospectra and by computing cross spectra.

All GPVA speeds were shifted to a height of $3.5 \mathrm{~m}$ with a stability dependent model of the wind in a constant flux layer. In Tables 2 and 3 , mean speeds at $3.5 \mathrm{~m}$ are also shown for the $\mathrm{B}$ and $\mathrm{K}$ wind recorders. These shifts were made assuming neutral stability, since the air and sea temperatures at each buoy were not available. The stability corrections would affect these mean $3.5-\mathrm{m}$ speeds by about $\pm 1 \%$. The applied corrections were 1.03 to the B winds, 1.05 to $\mathrm{K} 3$, and 0.94 to $\mathrm{K} 2$, while no corrections were needed for the VAWR and VMWR's, because they were positioned at $3.5 \mathrm{~m}$.

The basic statistics from the two periods (Table 2 for the first time period and Table 3 for the second time period) show differences in the direction and speed of the mean wind vectors. The largest direction differences, those between the B mooring AWR's and the other sensors, persist for long periods of time but jump abruptly from one value to the next, suggesting a problem with the compasses of those instruments (Figure 7). Some difference in mean speeds was expected from spatial gradients in the wind field. Wind data from the ships at the corners of the meteorological triangle and the sea level pressure maps suggest mean horizontal gradients of wind speed of about $1 \mathrm{~m} \mathrm{~s}^{-1}$ per $200 \mathrm{~km}$ [Brown and Liu, 1982]. Thus between $\mathrm{H} 2$ at the north and the FIA the difference in mean wind speeds may be about $0.2 \mathrm{~m} \mathrm{~s}^{-1}$. The two VMWR's, one at $\mathrm{H} 2$ and one at W2, show a measured difference in mean speed of that size, $0.15 \mathrm{~m} \mathrm{~s}^{-1}$, in the first intercomparison period, consistent with the mesoscale gradient. However, the two wind instruments on W2 also show, in the same period, a measured difference of

TABLE 3. August 27 to September 2

\begin{tabular}{|c|c|c|c|c|c|c|c|c|c|}
\hline Sensor & $\mathrm{m} \mathrm{s}^{-1}$ & $\mathrm{~m} \mathrm{~s}^{-1}$ & $\begin{array}{c}\bar{s}, \\
\mathrm{~m}^{-1}\end{array}$ & $\begin{array}{l}\bar{s}_{3.5}, \\
\mathrm{~m} \mathrm{~s}^{-1}\end{array}$ & $\theta=\underset{\operatorname{deg}}{\tan ^{-1}(\tilde{v} / \tilde{u}),}$ & $\begin{array}{c}\left(\tilde{u}^{2}+\bar{v}^{2}\right)^{1 / 2} \\
\mathrm{~m} \mathrm{~s}^{-1}\end{array}$ & $\begin{array}{c}\theta-\theta_{\text {VAwR }}, \\
\text { deg }\end{array}$ & $\tilde{s} / \tilde{s}_{\text {VAWR }}$ & $\bar{s}_{3.5} / \bar{s}_{3.5 \mathrm{VAWR}}$ \\
\hline W2 VAWR & 4.60 & -1.75 & 6.41 & 6.41 & 110.8 & 4.92 & 0.0 & 1.00 & 1.00 \\
\hline $\mathrm{H} 2$ VMWR & 4.07 & -1.30 & 5.90 & 5,90 & 107.7 & 4.43 & -3.1 & 0.92 & 0.92 \\
\hline B1 AWR & 3.44 & -2.62 & 6.19 & 6.38 & 127.3 & 4.32 & 16.5 & 0.97 & 1.00 \\
\hline B2 AWR & 4.44 & -1.38 & 6.11 & 6.29 & 107.3 & 4.64 & -3.5 & 0.95 & 0.99 \\
\hline B3 AWR & 4.10 & -1.87 & 6.10 & 6.28 & 114.5 & 4.24 & 3.7 & 0.95 & 0.99 \\
\hline B4 AWR & 4.08 & 1.76 & 6.02 & 6.20 & 66.7 & 4.44 & -44.1 & 0.94 & 0.97 \\
\hline K2 AWR & 3.30 & -2.10 & 5.37 & 5.03 & 122.5 & 3.91 & 11.7 & 0.84 & 0.78 \\
\hline K3 AWR & 2.42 & -3.51 & 5.68 & 5.96 & 124.6 & 4.26 & 13.8 & 0.89 & 0.94 \\
\hline \multicolumn{10}{|l|}{ Meteor } \\
\hline GPVA* & & & 5.64 & 5,64 & & & & 0.95 & 0.95 \\
\hline
\end{tabular}

* Comparison based on times when GPVA data were available, which amounted to $95 \%$ of the duration of this intercomparison period. 


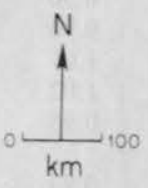

B1 B2-B3 -.. B4-
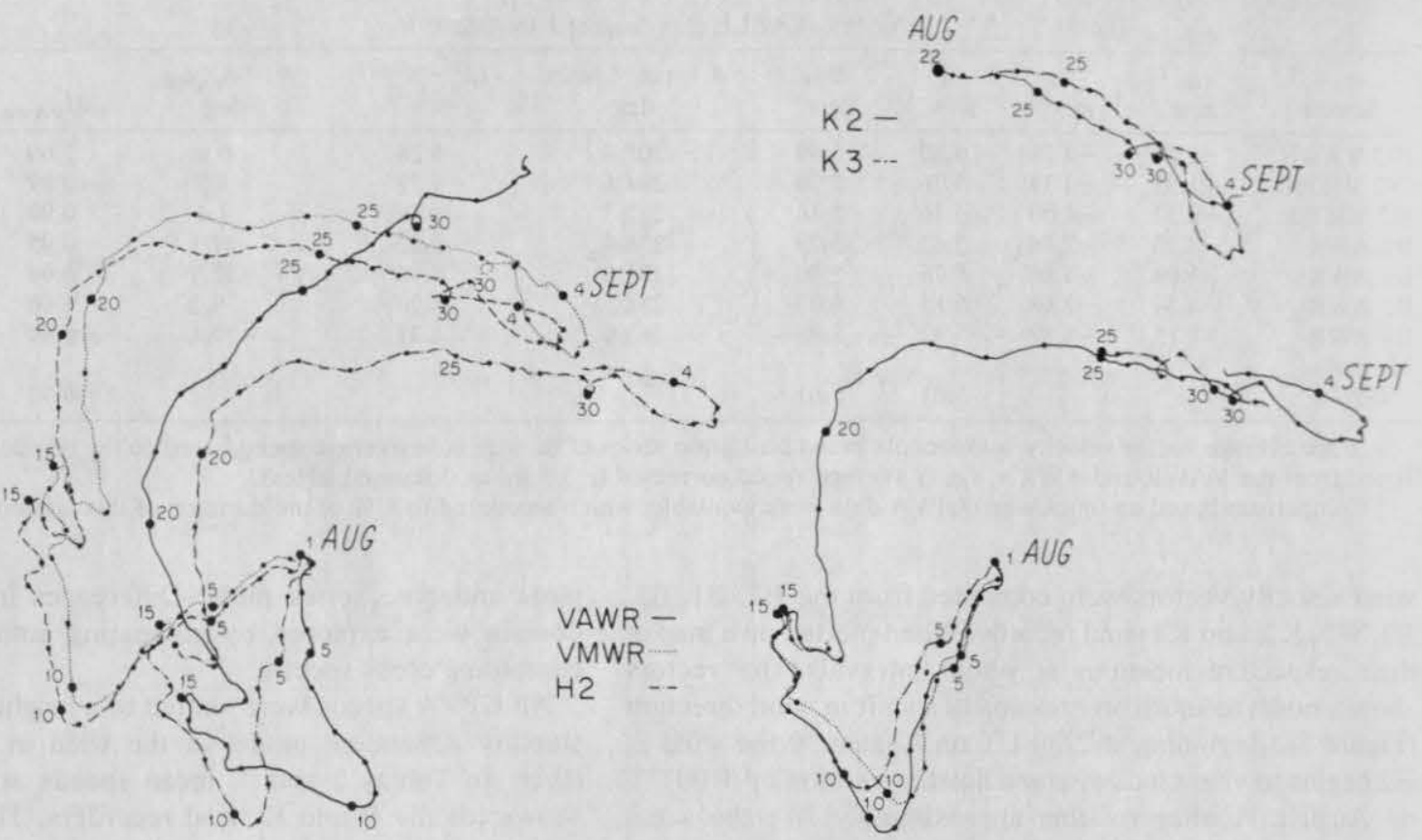

Fig. 7. Progressive vector diagrams of the wind records from the $\mathrm{H}, \mathrm{W}, \mathrm{B}$, and $\mathrm{K}$ moorings. Differences in length and orientation result from differences in measured speed and direction of the wind by the different instruments. The B AWR records are plotted from a common point, starting August 1. The W2 and $\mathrm{H} 2$ records are plotted from a common point, starting August 1. The K AWR's are plotted from a common point, starting August 22.
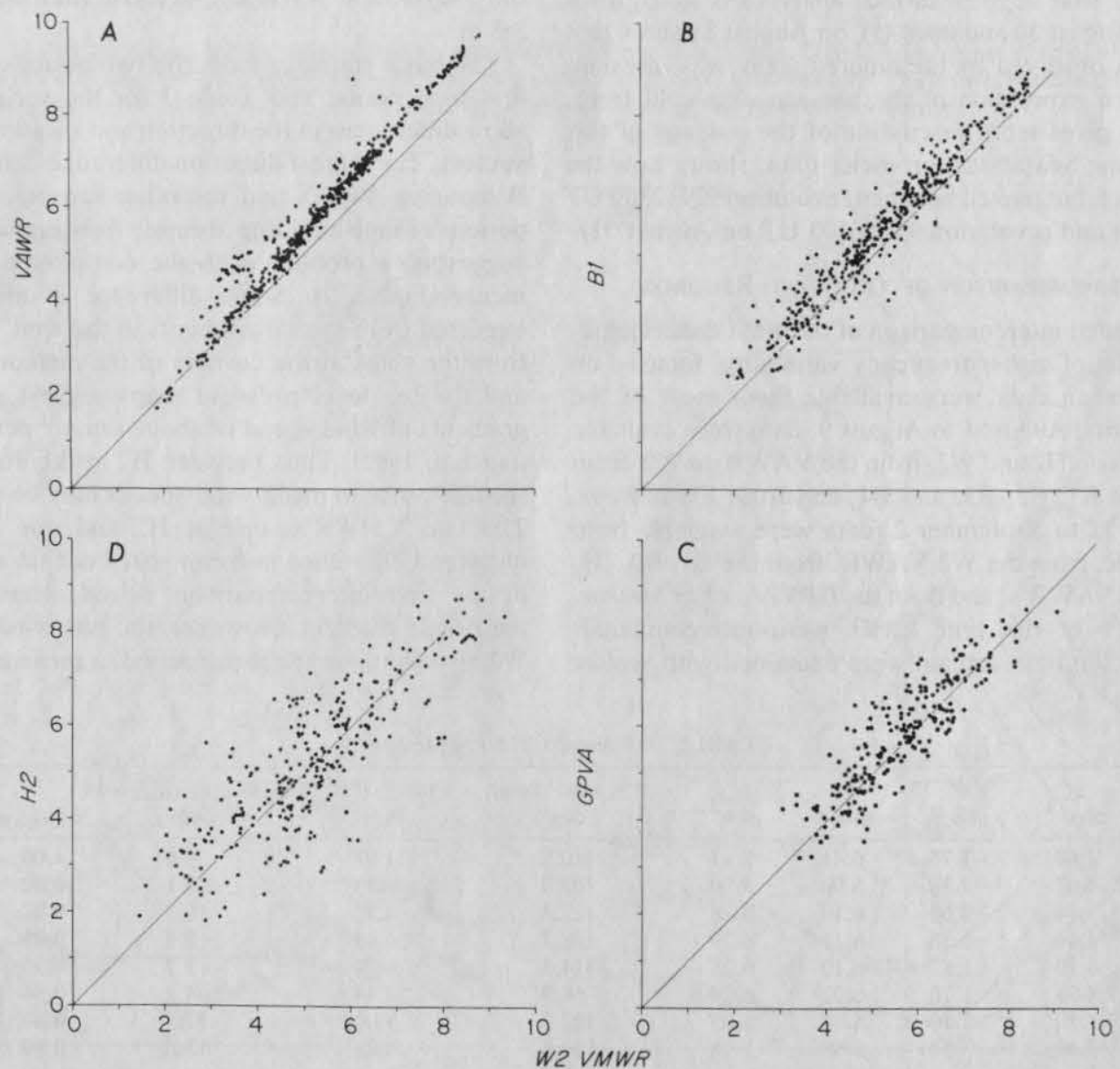

Fig. 8. Scatter plots intercomparing wind speed from $(a)$ the W2 VAWR $(3.5 \mathrm{~m}),(b)$ the B1 AWR $(2.5 \mathrm{~m}),(\mathrm{c})$ the GPVA $(3.5 \mathrm{~m})$, and $(d)$ the H2 VMWR $(3.5 \mathrm{~m})$ with speed data from the W2 VMWR $(3.5 \mathrm{~m})$ for the period of August 1-9. 1978. The speeds are in meters per second. Solid lines indicate the $45^{\circ}$ or $1: 1$ line. 

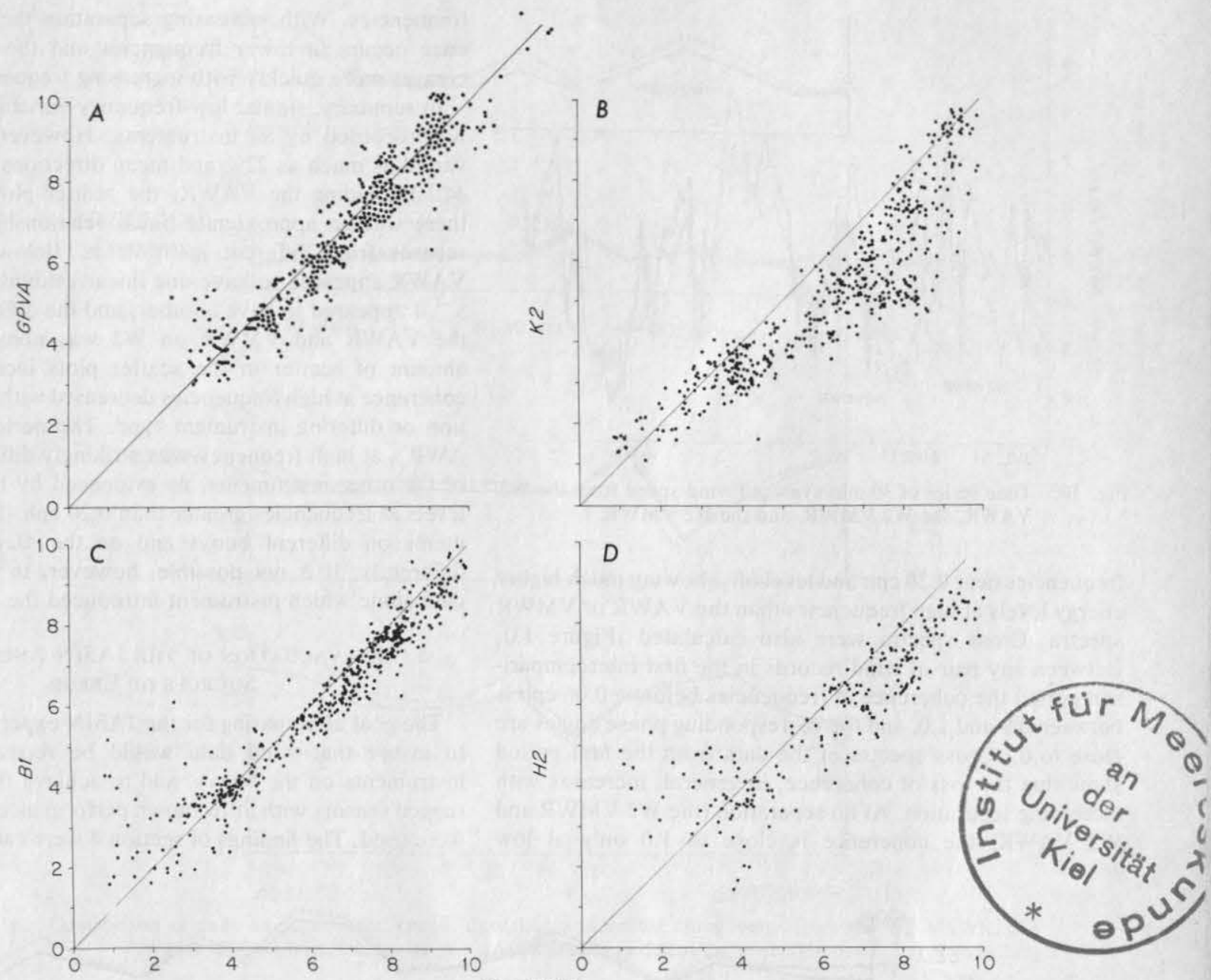

Fig. 9. Scatter plots intercomparing wind speed from $(a)$ the GPVA $(3.5 \mathrm{~m}),(b)$ the K2 AWR $(7.7 \mathrm{~m}),(c)$ the B1 AWR $(2.5 \mathrm{~m})$, and $(d)$ the H2 VMWR $(3.5 \mathrm{~m})$ with the W2 VAWR $(3.5 \mathrm{~m})$ speeds for the period of August 27 to September 2, 1978. The speeds are in meters per second. Solid lines indicate the $45^{\circ}$ or 1:1 line.

$0.63 \mathrm{~m} \mathrm{~s}^{-1}$, or approximately $11 \%$, showing that there is significant error in the mean wind speeds recorded by one or both of the instruments on W2.

For the first intercomparison period, all the records were compared in the time domain to the W2 VMWR. Scatter plots (Figures $8 a, 8 b, 8 c$, and $8 d$ ) show that within the limitations imposed by differences in sensors and recording techniques all wind speeds except those from the VAWR scatter roughly about a 1 to 1 relation with the other wind speeds. At a speed of about $4 \mathrm{~m} \mathrm{~s}^{-1}$ the VAWR-VMWR relationship changes, and above $6 \mathrm{~m} \mathrm{~s}^{-1}$ the VAWR speeds are approximately $0.7 \mathrm{~m} \mathrm{~s}^{-1}$ higher than the VMWR speeds. In Figure 9, data from the second intercomparison period are plotted against the W2 VAWR data, since the W2 VMWR had failed by this time. In general, the scatter plots show similar features to Figure 8 in that above $4 \mathrm{~m} \mathrm{~s}^{-1}$ the VAWR speeds were consistently higher than other speeds.

It is important to emphasize the time-dependent nature of the performance of the wind recorders. At times, especially in moderate ( 3 to $6 \mathrm{~m} \mathrm{~s}^{-1}$ ) winds, the W2 VAWR wind speeds were much higher than the VMWR winds; these times are the source of the points in Figure $8 a$ that lie above the bulk of the data points. No cause for this behavior could be determined. For July 31 to August 5 time series plots of the wind speed, averaged over $30 \mathrm{~min}$, from the W2 VAWR, the W2 VMWR, and the H2 VMWR show (Figure 10) this lack of stationarity in the differences between the speeds. The VAWR record cannot be brought into agreement with the W2 VMWR either by multiplying by a constant or applying an offset. It is possible that the statistics shown in Tables 2 and 3 are biased by the complicated nature of the wind time series. In particular, the mean wind speeds for each time period, though important statistics, may be biased, and the ratios of speeds in the tables may not reflect the relative performance of the sensors during smaller segments of the time series. As a check, the statistics were computed for nonoverlapping 24-hour segments of the time series, and the results supported the findings presented in Tables 2 and 3. There is some variation in time of the relative performance of the wind recorders, particularly in relative magnitudes of the vector components of the wind, and the 24-hour averages are shown for two longer segments of the JASIN experiment in Figures $11 a$ and $11 b$.

Autospectra of the wind velocity time series were computed for both the first and second (Figure 12) periods. (These autospectra are the sum of the autospectra of $u$ and of $v$ and thus show an energy level proportional to the kinetic energy.) The most striking difference between the autospectra is that while all are red at low frequencies with a slope of between -4 and -3 , those of the AWR data change slope at 


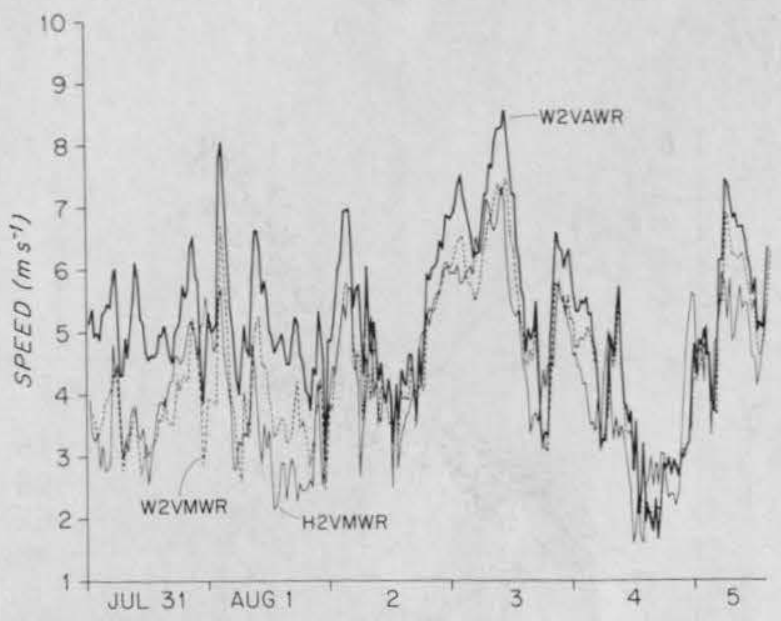

Fig. 10. Time series of 30-min-averaged wind speed from the W2 VAWR, the W2 VMWR, and the H2 VMWR.

frequencies near $0.20 \mathrm{cph}$ and level off, showing much higher energy levels at high frequencies than the VAWR or VMWR spectra. Cross spectra were also calculated (Figure 13). Between any pair of wind records in the first intercomparison period the coherence at frequencies below $\sim 0.06 \mathrm{cph}$ is between 0.9 and 1.0 , and the corresponding phase angles are close to $0^{\circ}$. Cross spectra of the data from the first period show that the loss of coherence, in general, increases with increasing separation. At no separation (the W2 VMWR and W2 VAWR) the coherence is close to 1.0 only at low frequencies. With increasing separation the loss of coherence occurs at lower frequencies and the coherence decreases more quickly with increasing frequency.

In summary, similar low-frequency variability of the wind was recorded by all instruments. However, mean speeds varied as much as $22 \%$ and mean directions by as much as $44^{\circ}$. Excluding the VAWR, the scatter plots showed that there was an approximate linear relationship between the records from different instruments. Below $4 \mathrm{~m} \mathrm{~s}^{-1}$ the VAWR appeared to have one linear calibration; above $6 \mathrm{~m}$ $\mathrm{s}^{-1}$ it appeared to have another, and the difference between the VAWR and VMWR on W2 was nonstationary. The amount of scatter in the scatter plots increased and the coherence at high frequencies decreased with greater separation or differing instrument type. The performance of the AWR's at high frequency was strikingly different from that of the other instruments, as evidenced by the high energy levels at frequencies greater than $0.20 \mathrm{cph}$. Different instruments on different buoys and on the Meteor performed differently. It is not possible, however, to judge from the data alone which instrument introduced the least error.

\section{Reevaluation of the JASIN Anemometers; SOURCES OF ERROR}

The goal in preparing for the JASIN experiment had been to insure that wind data would be recovered from the instruments on the buoys, and to achieve that goal, rather rugged sensors with little known performance characteristics were used. The findings of section 4 were cause for concern
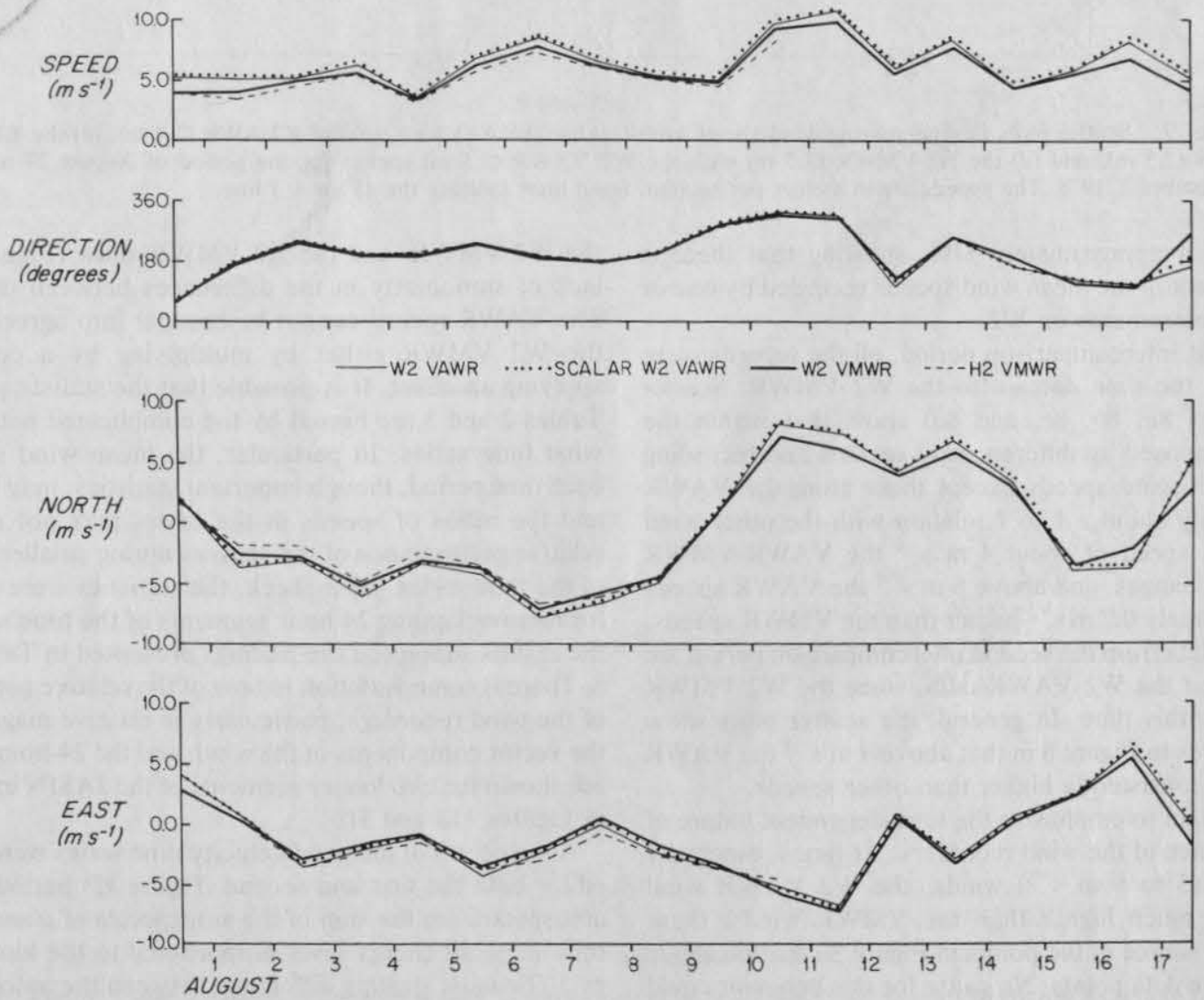

Fig. 11a. Comparison of daily averaged wind speed, direction, and vector components from the W2 VAWR, W2 VMWR, and H2 VMWR. The scalar W2 VAWR record is discussed in section 6. 

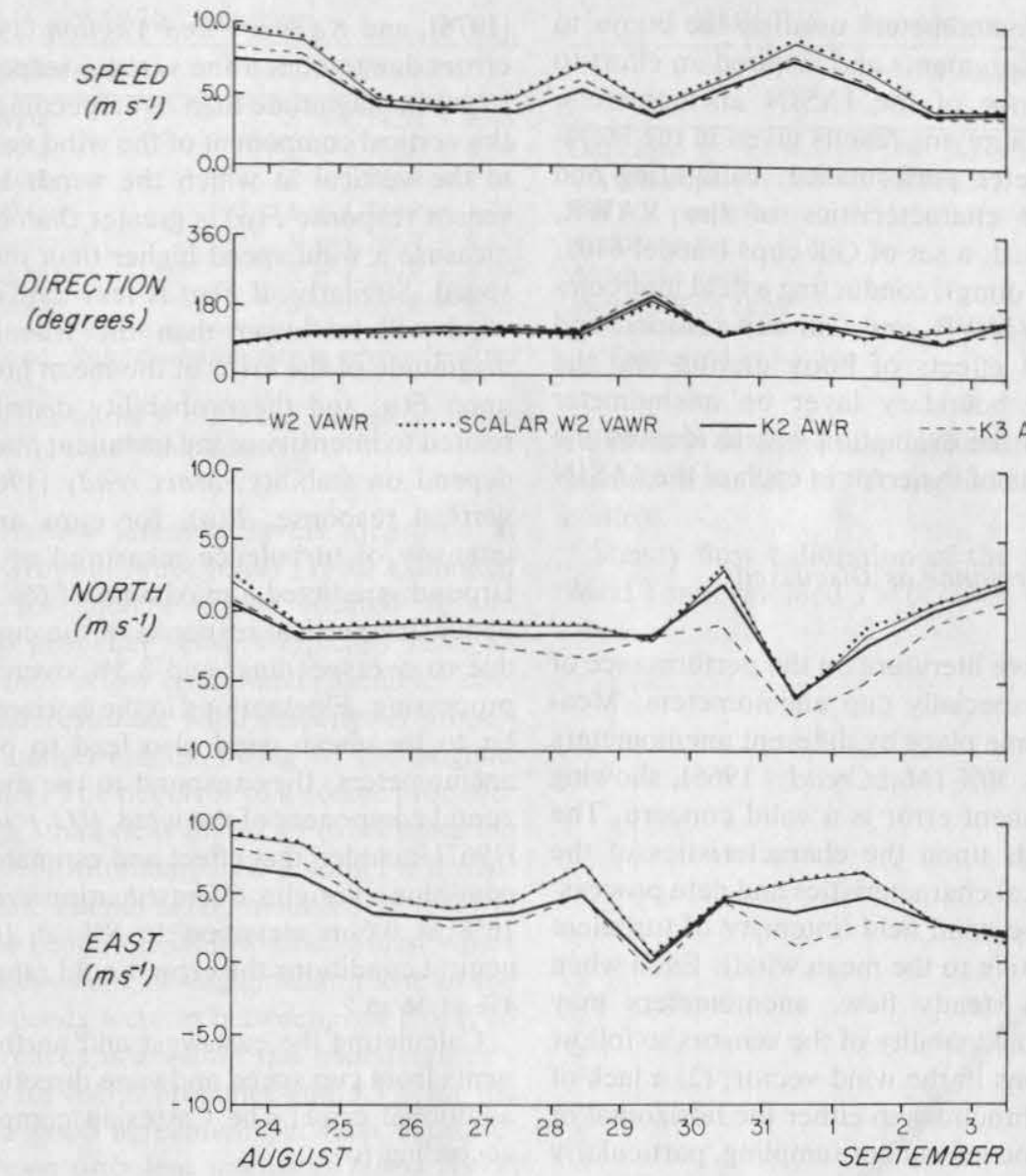

Fig. $11 b$. Comparison of daily averaged wind speed, direction, and vector components from the W2 VAWR, K2 AWR, and K3 AWR. The scalar W2 VAWR record is discussed in section 6.

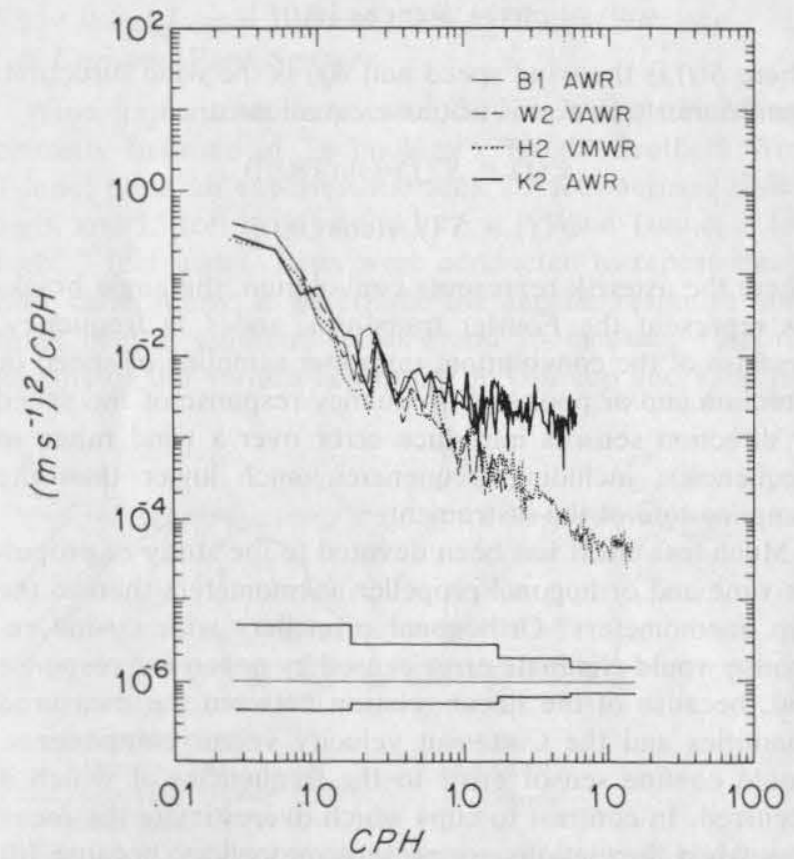

Fig. 12. Autospectra of the wind velocity records from the second intercomparison period (August 27 to September 2). The coverage of the high frequencies differs because of the different sampling rates of the instruments; all autospectra have been calculated from the original time series and band averaged in the same way. Ninety-five percent confidence limits are shown.

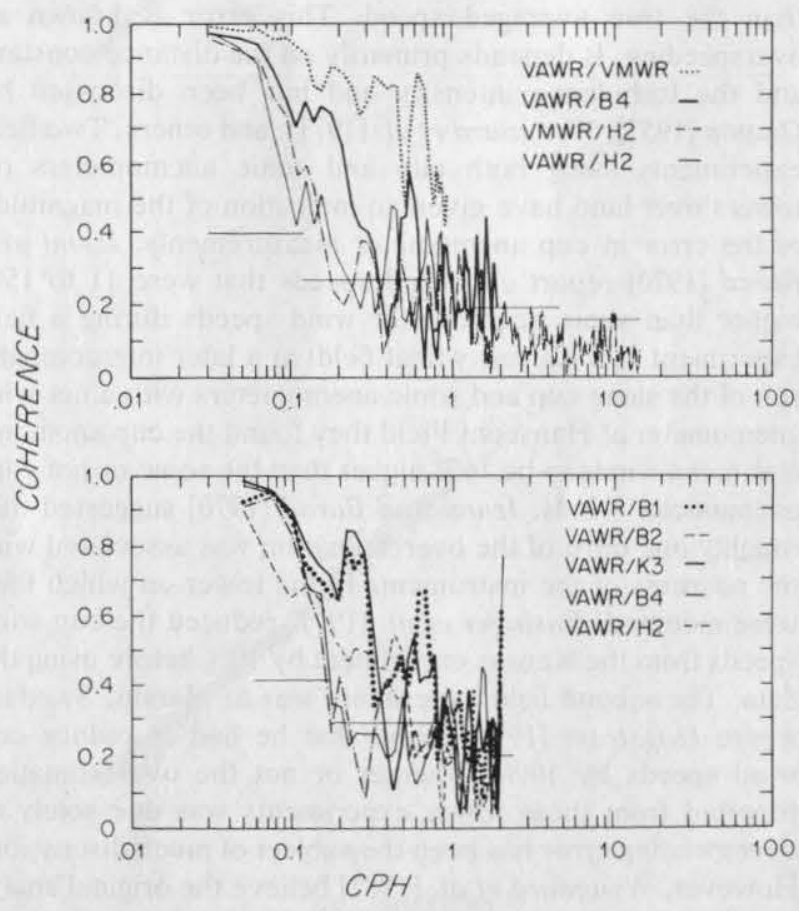

Fig. 13. Coherence between various wind records with increasing spatial separation from (top) the first intercomposition period and (bottom) the second intercomparison period. The horizontal lines are the $95 \%$ confidence levels. 
about the ability of the anemometers used on the buoys to make accurate wind measurements and inspired an effort to reevaluate the performance of the JASIN anemometers. This evaluation involved applying results given in the literature describing anemometer performance; calibrating and measuring the response characteristics of the VAWR, VMWR, and, as a standard, a set of Gill cups (model 6101, manufactured by R. M. Young); conducting a field intercomparison of the VAWR, VMWR, and Gill cup sensors; and estimating the additional effects of buoy motion and the structure of the marine boundary layer on anemometer performance. The goal of the evaluation was to identify the probable sources and sizes of the error in each of the JASIN wind records.

\subsection{Anemometer Performance as Discussed in the Literature}

There exists an extensive literature on the performance of rotating anemometers, especially cup anemometers. Measurements made in the same place by different anemometers may differ by as much as $30 \%$ [MacCready, 1966], showing that the size of measurement error is a valid concern. The size of the error depends upon the characteristics of the instrument (sensor physical characteristics and data processing techniques) and of the wind field (intensity of turbulent velocity fluctuations relative to the mean wind). Even when accurately calibrated in steady flow, anemometers may introduce error from (1) the inability of the sensors to follow high-frequency fluctuations in the wind vector, (2) a lack of cosine angular response functions in either the horizontal or vertical or both, and (3) too infrequent sampling, particularly of direction, resulting in aliasing.

Cup anemometers respond to rapid increases in wind speed more quickly than to rapid decreases. As a result of this asymmetric response the measured wind speed is higher than the true averaged speed. This error is known as overspeeding. It depends primarily on the distance constant and the turbulence intensity and has been discussed by Onuma [1957], Wyngaard et al. [1971], and others. Two field experiments using both cup and sonic anemometers on towers over land have given an indication of the magnitude of the error in cup anemometer measurements. Izumi and Barad [1970] report cup wind speeds that were 11 to $15 \%$ higher than sonic anemometer wind speeds during a field experiment at a Kansas wheat field; at a later intercomparison of the same cup and sonic anemometers with a hot wire anemometer at Hanscom Field they found the cup anemometer mean winds to be $16 \%$ higher than the sonic or hot wire anemometer winds. Izumi and Barad [1970] suggested that roughly one third of the overestimation was associated with the nearness of the instruments to the tower on which they were mounted, Businger et al. [1971] reduced the cup wind speeds from the Kansas experiment by $10 \%$ before using the data. The second field experiment was at Marsta, Sweden, where Hogstrom [1974] found that he had to reduce cup wind speeds by $10 \%$. Whether or not the overestimation reported from these tower experiments was due solely to overspeeding error has been the subject of much discussion. However, Wyngaard et al. [1982] believe the original analysis of the Kansas data is still valid. It is clear that overspeeding did exist, even with the light weight, high-performance cups that were used.

Hyson [1972], McBean [1972], Busch and Kristensen
[1976], and Kaganov and Yaglom [1976] have stressed that errors due to noncosine vertical response may be as large or larger in magnitude than overspeeding error. Fluctuations in the vertical component of the wind velocity shift $\alpha$, the angle in the vertical at which the winds hits the sensor. If the sensor response $F(\alpha)$ is greater than $\cos (\alpha)$, the sensor will measure a wind speed higher than the true horizontal wind speed. Similarly, if $F(\alpha)$ is less than $\cos (\alpha)$, the measured wind will be lower than the true horizontal wind. The magnitude of the error in the mean horizontal wind depends upon $F(\alpha)$ and the probability distribution of $\alpha$, which is related to intensity of the turbulent fluctuations which in turn depend on stability. MacCready [1966], using a measured vertical response, $F(\alpha)$, for cups and time series of the intensity of turbulence measured at White Sands Proving Ground, predicted a maximum of $6 \%$ overestimation due to noncosine vertical response of the cups, $1 \%$ overestimation due to overspeeding, and $3.5 \%$ overestimation due to data processing. Fluctuations in the horizontal plane perpendicular to the mean wind also lead to overestimation by cup anemometers; they respond to the mean speed of the horizontal component of the wind, $\left[\left(U+u^{\prime}\right)^{2}+v^{\prime 2}\right]^{1 / 2}$. Bernstein [1967] included that effect and estimated that under unstable conditions the cup overestimation error would range from $16 \%$ at $0.5-\mathrm{m}$ elevation to $8 \%$ at $16-\mathrm{m}$ elevation; under neutral conditions the error would range from $8 \%$ at $0.5 \mathrm{~m}$ to $4 \%$ at $16 \mathrm{~m}$.

Calculating the east-west and north-south vector components from cup speed and vane direction data may introduce additional error. The Cartesian components are calculated according to

$$
u(t)=S(t) \sin [\theta(t)]
$$

and

$$
v(t)=S(t) \cos [\theta(t)]
$$

where $S(t)$ is the wind speed and $\theta(t)$ is the wind direction. The Fourier transforms of those equations are

$$
\begin{aligned}
& u^{\prime}(f)=S^{\prime}(f) *\{\sin [\theta(t)]\rangle \\
& v^{\prime}(f)=S^{\prime}(f) *\langle\cos [\theta(t)]\rangle
\end{aligned}
$$

where the asterisk represents convolution, the angle brackets represent the Fourier transform, and $f$ is frequency. Because of the convolution, improper sampling of speed or direction and/or poor high-frequency response of the speed or direction sensors introduce error over a wind range of frequencies, including frequencies much lower than the sampling rate of the instrument.

Much less effort has been devoted to the study of propeller-vane and orthogonal propeller anemometers than to the cup anemometers. Orthogonal propellers with cosine response would eliminate error caused by noncosine response and, because of the linear relation between the measured quantities and the Cartesian velocity vector components, would confine sensor error to the frequencies at which it occurred. In contrast to cups which overestimate the mean flow when fluctuations are present, propellers, because lift as well as drag forces are important, underestimate the mean flow in the presence of fluctuations parallel to the mean flow [Busch et al., 1980; Davis and Weller, 1980]. MacCready's [1966] study included propeller-vane and propeller sensors. Fully orienting propeller-vane sensors overestimate the 
TABLE 4. VAWR Calibrations

\begin{tabular}{lcc}
\hline Date & Cup Material & Calibration* \\
\hline 1972 & Mylar & $S=1.742 R+0.48$ \\
1972 & Mylar & $S=1.752 R+0.59$ \\
1980 & Mylar & $S=1.756 R+1.08$ \\
1980 & Mylar & $S=1.740 R+1.74$ \\
1980 & Lexan & $S=1.766 R+0.82$ \\
1980 & Lexan & $S=1.739 R+0.99$ \\
$1980^{+}$ & Lexan & $S=1.677 R+0.68$ \\
\hline
\end{tabular}

${ }^{*} S$ is in meters per second; $R$ is revolution rate in revolutions per second.

†This calibration was done in the $5 \times 7$ Wind Tunnel; all others were done in the Wright Brothers Wind Tunnel.

mean wind; using turbulent intensity levels measured at White Sands Proving Ground, MacCready [1966] estimated that maximum error for such a sensor located at 4-m elevation is $8 \%$. Fixed propeller sensors typically have an angular response that falls below cosine and resembles $\cos ^{2}$ $(\theta)$ and, as a result, underestimate wind velocity. A propeller-vane sensor may underestimate owing to the angular response of the propeller. The net error of a cosine propeller [MacCready, 1966] is a small (less than 1\%) overestimation error. Smith et al. [1976] intercompared a sonic, a thrust, and a Gill propeller-vane anemometer, mounted 10 to $13 \mathrm{~m}$ above sea level on the beach of Sable Island. Mean winds from the GPVA were less than $5 \%$ higher than those of the sonic, and the thrust speeds were in between, but closer to the GPVA. The differences are within the manufacturer's specifications of $\pm 2 \%$ for a Gill propeller and $\pm 3 \%$ for the sonic. There was also good agreement between measurements of the downstream turbulent intensity. Horst [1973] reports that mean winds measured by a Gill $u v w$ propeller anemometer were approximately $5 \%$ higher than those measured by sonic anemometers.

\subsection{Wind Tunnel Tests of the VAWR, VMWR, and Gill Cup and Vane Sensors}

Wind tunnel tests were conducted in 1980 at the Massachusetts Institute of Technology's Wright Brothers Wind Tunnel (with an experimental area 7.5 feet across, 10 feet high, and 15 feet long) and at its $5 \times 7$ Wind Tunnel ( 5 feet high, 7 feet wide). Tests were conducted to repeat steady flow calibrations, to determine the angular response functions of the different sensors and to measure response lengths of the various sensors. The Gill cup and vane had
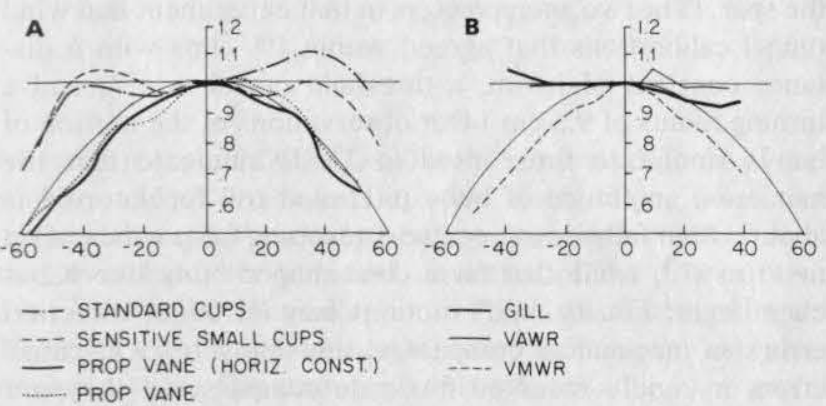

Fig. 14. Vertical response functions $F(\alpha)$ [from MacCready, 1966] are shown in Figure $14 a$ for two different cup anemometers, a propeller-vane anemometer where the vane is constrained to remain in the horizontal plane, and a fully orienting propeller-vane sensor. Vertical response functions shown in Figure $14 b$ were measured in the wind tunnel. A cosine curve is drawn in Figures $14 a$ and $14 b$ for reference. Positive angles indicate tilt toward the wind.
TABLE 5. Anemometer Distance Constants

\begin{tabular}{lcc}
\hline & $\begin{array}{c}\text { Measured, } \\
\mathrm{m}\end{array}$ & $\begin{array}{c}\text { Manufacturer's } \\
\text { Specification, m }\end{array}$ \\
\hline Gill cups & $3.5 \pm 0.2$ & 3.7 \\
VAWR cups & $14.5 \pm 2$ & \\
VMWR propellers & $10.9 \pm 0.8$ & 5 \\
Aanderaa cups & & 4 \\
Aanderaa vane & & 1.5 \\
Burt's [1975] cups* & & \\
\hline
\end{tabular}

*Discussed in section 5.4.

calibration data and response characteristics provided by the manufacturer (R. M. Young) and served as an experimental control.

Steady flow calibration of the Gill cup set in the $5 \times 7$ Wind Tunnel yielded $S=0.72 R+0.2$, where $S$ is wind speed
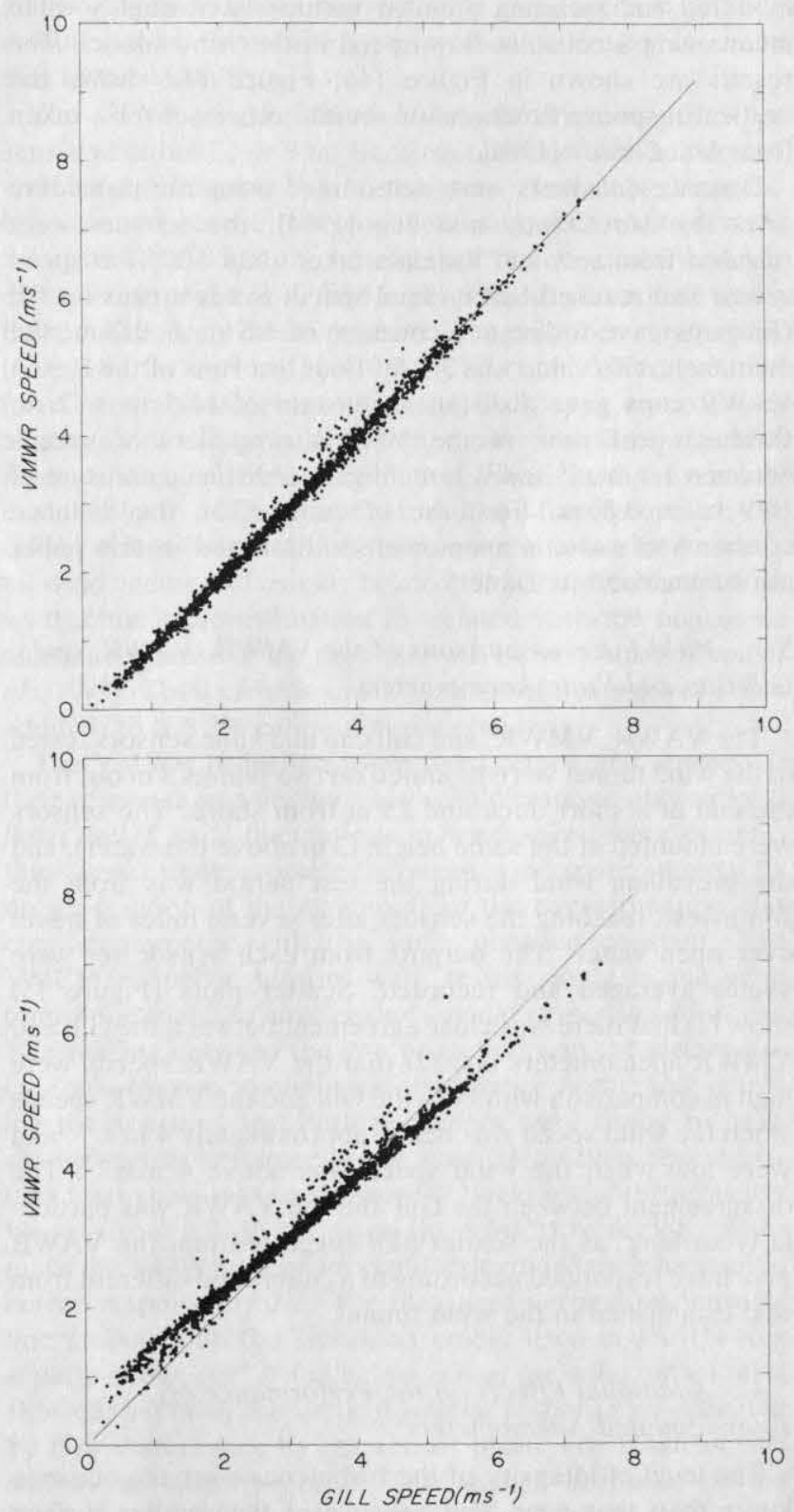

Fig. 15. Scatter plots of the data from the dock intercomparison. (Top) Comparison of VMWR and Gill cup speeds; (bottom) comparison of VAWR and Gill speeds. Solid lines indicate the $45^{\circ}$ or 1:1 line. 
in meters per second and $R$ is cup revolution rate in revolutions per second. The manufacturer's calibration was $S=0.75 R+0.3$. Table 4 summarizes the calibration history of the VAWR. $S=1.75 R+0.5$ was the calibration used to interpret the JASIN 1978 W2 VAWR data. The original design testing and calibration of the VMWR sensors had been done at the Applied Mechanics and Engineering Science department's wind tunnel at the University of California, San Diego [Weller, 1978]. Calibration of three instruments before JASIN found a calibration of $S=0.375 R$. The actual instruments used in JASIN did not survive the experiment. A VMWR sensor assembly was borrowed from Scripps Institution of Oceanography (Russ Davis) for the wind tunnel tests, and for the pier test a complete VMWR was borrowed.

The vertical response functions, $F(\alpha)$, of the sensors were measured by tilting the plate to which the sensors were mounted and inclining them at various fixed angles while maintaining a constant flow speed in the wind tunnel. The results are shown in Figure 14b; Figure 14a shows the vertical response functions of several other sensors, taken from MacCready [1966].

Distance constants were determined using the procedure given by MacCready and Jex [1964]; the sensors were released from rest and the data taken only after the speed sensor had reached half its final speed. Six test runs on the Gill cups gave a distance constant of $3.5 \mathrm{~m} \pm 0.2 \mathrm{~m}$; the manufacturer's value was $3.7 \mathrm{~m}$. Four test runs of the Lexan VAWR cups gave a distance constant of $14.5 \mathrm{~m} \pm 2 \mathrm{~m}$. Fourteen test runs of the VMWR propellers at speeds between $1.4 \mathrm{~m} \mathrm{~s}^{-1}$ and $7.3 \mathrm{~m} \mathrm{~s}^{-1}$ gave a distance constant of $10.9 \mathrm{~m} \pm 0.8 \mathrm{~m}$. For ease of comparison the distance constants of various anemometers discussed in this paper are summarized in Table 5 .

\subsection{Field Intercomparisons of the VMWR, VAWR, and Gill Cup and Vane Anemometers}

The VAWR, VMWR, and Gill cup and vane sensors tested in the wind tunnel were mounted on two pilings $5 \mathrm{~m}$ out from the end of a short dock and $25 \mathrm{~m}$ from shore. The sensors were mounted at the same height ( $3 \mathrm{~m}$ above the water), and the prevailing wind during the test period was from the southwest, reaching the sensors after several miles of travel over open water. The outputs from each sensor set were vector averaged and recorded. Scatter plots (Figure 15) show (1) that there was close agreement between the Gill and VMWR anemometers and (2) that the VAWR speeds were high in comparison with both the Gill and the VMWR speeds when the wind speed was below approximately $4 \mathrm{~m} \mathrm{~s}^{-1}$ and were low when the wind speed was above $4 \mathrm{~m} \mathrm{~s}^{-1}$. The disagreement between the Gill and the VAWR was particularly striking, as the scatter plot suggested that the VAWR may have responded according to a calibration different from that established in the wind tunnel.

\subsection{Additional Effects on the Performance of Buoy-Mounted Anemometers}

The level of intensity of the turbulence over the ocean is lower than that over land because of the smaller surface drag. Kondo et al. [1971] estimate that mechanical anemometer measurement error over the land during the day is 3 to 4 times larger than that over the land at night which in turn is two times larger than that over the sea. Thus lack of vertical cosine response in a wind sensor mounted on a fixed platform would cause less error over the ocean than over land. Also the mean wind speed and mean horizontal component of the wind differ by only $0.5 \%$ over the ocean [Pond et al., 1979]. On the other hand, in a weakly buoyant boundary layer roll vortices are common [LeMone, 1980]. The pattern of flow associated with the roll vortices may at times cause the mean wind vector to be well out of the horizontal plane.

Further, ocean surface waves both affect the airflow over the water and cause movement of buoys and ships which affect wind sensor performance. The surface wave field in the JASIN area was studied with various wave rider and pitch-roll buoys [Stewart, 1980]. Daily averaged significant wave heights varied between 1 and $5 \mathrm{~m}$. Typical values of the daily averaged significant wave height were near $2 \mathrm{~m}$; the peak value of nearly $5 \mathrm{~m}$ occurred on August 19 following the strongest wind event. The frequency of the waves associated with the peak in the surface wave frequency spectra varied between $0.08 \mathrm{~Hz}$ and $0.15 \mathrm{~Hz}$, with a mean value of $0.12 \mathrm{~Hz}$. The disturbance of the airflow by the waves is limited to near the surface, at elevations of the order of one wave height [Hasse et al., 1977]. The motions of the buoy, both up and down heaving and side to side pitching and rolling, can introduce significant error. Pond [1968] notes that as a result of the buoy motion the sensors are tipped with respect to the horizontal, move up and down through the wind profile, and are displaced through a roughly elliptical path at the period of the dominant surface waves. Considering the W2 VAWR with its long-distance constant, $l_{0}=15 \mathrm{~m}$ at a height $z=3.5$ $\mathrm{m}$, suppose that the 3 -dbar down frequency, $f_{0}=U\left(2 \pi l_{0}\right)^{-1}$, is characteristic of the frequency above which the response is significantly asymmetric. The peak of the downstream turbulence spectrum, $f_{p}=0.01 \mathrm{U} / z=0.063 \cdot l_{0} \cdot f_{0} / z=$ $0.27 f_{0}$, is not much below $f_{0}$, so a lot of the turbulence produces overspeeding. At low wind speeds the entire wave spectrum contributes to overspeeding. For example, at $U=$ $4 \mathrm{~m} \mathrm{~s}^{-1}$ frequencies above $f_{0}=0.42 \mathrm{~Hz}$ or periods less than $23 \mathrm{~s}$ are not properly averaged. However, at higher winds, 10 $\mathrm{m} \mathrm{s}^{-1}$, for example, $f_{0}$ equals $0.11 \mathrm{~Hz}$ and only a portion of the wave spectrum (periods of less than $9.4 \mathrm{~s}$ ) gives rise to overspeeding. The effect of swell, therefore, will be more pronounced at low wind speeds. Field intercomparisons of identical cup anemometers $5 \mathrm{~m}$ above the sea surface on a stable spar buoy and an adjacent toroid buoy [Burt, 1975] found that the scalar-averaged mean winds from the more active toroid buoy were $7 \%$ higher than those measured from the spar. (The two anemometers in that experiment had wind tunnel calibrations that agreed within $1 \%$ cups with a distance constant of $1.5 \mathrm{~m}$, a threshold of $1.5 \mathrm{~m} \mathrm{~s}^{-1}$, and a turning radius of $9.5 \mathrm{~cm}$.) Our observations of the motion of buoys similar to those used in JASIN indicate that the maximum amplitude of buoy pitch and roll for a toroid is about $\pm 8^{\circ}$ in fully developed seas resulting from winds of up to $15 \mathrm{~m} \mathrm{~s}^{-1}$, while that for a cone-shaped buoy like $\mathrm{K} 2$ is even larger. Finally, buoy motions may introduce direction errors in mechanical compasses, and buoy tilt will cause errors in rigidly mounted flux gate compasses if they are inclined with respect to the vertical component of the earth's magnetic field.

\section{ReEVAluation of THE JASIN ANEMOMETERS:} A Retrospective Look at THE DAta

The magnitude of the total error in measurements of the wind by a mechanical anemometer is related to the platform 
motion, to the level of intensity of the fluctuations in the apparent wind reaching the sensors, to the performance characteristics of the sensors, and to the way in which the Cartesian components of the wind are computed. Because buoy motions and fluctuations in the true wind were not monitored, it is not possible to evaluate quantitatively the error in the measurements made by each JASIN anemometer, but it is possible to assess the performance of each of the JASIN instruments based on the results discussed in section 5 and to estimate the magnitude and sign of the error.

All the AWR's, both on the B moorings and the $\mathrm{K}$ moorings, recorded energy levels at high frequencies that were above those of the records from the VAWR, VMWR's, and GPVA. This was the result of the method in which the AWR's measure the wind velocity. The cups accumulate turns so that a scalar average speed is recorded, but only one instantaneous reading of direction is recorded. As discussed above, aliasing results. The VAWR recorded, in addition to vector-averaged velocity components, speed and an instantaneous direction; these were used to create a wind record sampled as by an AWR for comparison with the vectoraveraged VAWR wind record. The spectrum of the simulated AWR record had high-energy levels at high frequencies when compared with the spectrum of the vector-averaged record that was shown in Figure 12. The effect appeared at frequencies as low as $0.05 \mathrm{cph}$; at $2 \mathrm{cph}$ the simulated AWR record had an energy level 20 times that of the vectoraveraged record. The mean speed of the simulated AWR record was $2 \%$ higher than the mean speed of the vectoraveraged record. The VMWR and the VAWR avoid aliasing, because they compute vector-averaged Cartesian velocity components at a rapid rate.

The performance of cup anemometers, as shown by Burt [1975], is sensitive to buoy motion; a cup anemometer on a toroid had speeds $7 \%$ higher than one on a spar. All the JASIN cup anemometers were on active toroid or cone buoys. As discussed in section 5, a large source of error with sensitive cup anemometers is their noncosine response to flow out of the horizontal plane. On a rigid platform an estimate of the effect of the out of horizontal fluctuations is made (see, for example, MacCready [1966]) by taking the probability distribution of the angle $\alpha$, the wind with respect to the horizontal plane to be Gaussian. The measured mean wind $\bar{U}$ is then estimated by

$$
\bar{U}=\int_{-\pi / 2}^{\pi / 2} P(\alpha) U F(\alpha) d \alpha
$$

where $U$ is the total wind, $F(\alpha)$ is the vertical response of the sensor, and $P(\alpha)$ is the Gaussian distribution. Over the ocean, where the level of turbulent intensity is smaller than that over land, the standard deviation of the distribution, $P(\alpha)$, is smaller [SethuRaman, 1979] than that over land. However, surface wave height and thus buoy motion also have a roughly Gaussian probability distribution. The angle of incidence of the wind at the sensor on the buoy will be the sum of the angle $\alpha$, the angle of the wind with respect to the horizontal, and $\beta$, the angle of the inclination of the buoy. The probability distribution of the sum of the angles will be the convolution of the two probability distributions. Except in calm seas, $P(\alpha+\beta)$ will be broad, with a standard deviation greater than $P(\alpha)$ over land. In addition, there is evidence from JASIN [Ishida, 1980] of the presence of roll vortices. The wind tunnel tests on the VAWR and published data for cup sets show that both the VAWR and the AWR cup anemometers have vertical response functions greater than $\cos (\alpha)$. These instruments will measure a mean wind that is high in comparison with the true mean wind. The VAWR, because of the effect of the shielding around the cups on its vertical response function, will introduce larger error than the AWR's. Additional overspeeding errors are probably not negligible. The distance constant of the AWR cups is $5 \mathrm{~m}$ and of the VAWR cups is $15 \mathrm{~m}$. For comparison, Burt's [1975] cups had a distance constant of $1.5 \mathrm{~m}$. As a result, the VAWR overresponse should be greater, owing to both its vertical response function and its unresponsive cups, than the AWR overresponse. Extrapolating from Burt's [1975] results, the AWR winds may be at least $7 \%$ high and the VAWR wind may be $10 \%$ high. However, the additional error associated with the measurement of only instantaneous direction may bring the AWR error closer to that of the VAWR.

The GPVA on the Meteor was an orienting propeller sensor at either 22 or $9 \mathrm{~m}$. Because turbulent scales increase with height, because the Meteor was more stable than the buoys, and because the propellers were fast response sensors, the GPVA had the potential (if the effect of the ship's disturbance of the flow field is properly dealt with) to make the most accurate measurements. The propeller-vane sensor $\left(l_{0}=0.8 \mathrm{~m}, z=9 \mathrm{~m}, f_{0}=0.2 \mathrm{~m}^{-1} U, f_{p}=0.006 f_{0}\right)$ should have been able to properly average all wave motions and almost all of the turbulent fluctuations. The Gill propellers have an angular response function that falls slightly below cosine [Horst, 1973]. However, unlike a fixed propeller, the GPVA orients into the wind, and over the ocean the horizontal wind vector will usually be close to parallel to the GPVA, so that the underestimation associated with the noncosine angular response of the propeller will be very small [Pond et al., 1979]. Total error is small, perhaps of the order of $1 \%$ in addition to $\mathrm{a} \pm 2 \%$ calibration uncertainty.

The VMWR propellers were fixed orthogonal sensors. If their response was cosine, they would respond only to axial flow, and if axial fluctuations in wind speed were present, they would underestimate the mean wind speed, though by only a fraction of the magnitude of the overestimation of a cup anemometer with the same distance constant. The VMCM propeller sensors were tested singly in the wind tunnel and found to have cosine angular response within $1 \%$. The spacing between the two propellers and the electronics case was chosen to minimize disturbance of the flow reaching the sensors, and both propellers were found to have cosine angular response in the water. However, recent tow tank tests show that decreasing the thickness of the propeller blades (from $0.3176 \mathrm{~cm}$ as on the VMCM to $0.1588 \mathrm{~cm}$ ) to make the VMWR propellers lighter degraded their horizontal cosine response by $3 \%$. The measured vertical response of one propeller on the sensor assembly used in JASIN was slightly above $\cos ^{2} \alpha$ and below $\cos \alpha$; the wind tunnel tests showed that in air the vertical angular response was affected by flow disturbance by the sensor itself. The result of this will be an underresponse. The angular response of the VMWR propeller is not as far from $\cos (\alpha)$ as that of the VAWR cup, and the VMWR propeller is more responsive than the VAWR cup set. The VMWR, then, may have underestimated the mean wind by something of the order of $3 \%$. 
TABLE 6. Percent Difference Between the Mean Wind Speeds From the Various Instruments and the GPVA for Intercomparison Periods 1 and 2

\begin{tabular}{lccc}
\hline & Period 1 & Period 2 & $\begin{array}{c}\text { Performance } \\
\text { Estimate* }\end{array}$ \\
\hline W2 VAWR & +7 & +5 & $+10 \pm ?$ \\
W2 VMWR & -4 & -3 & -3 \\
H2 VMWR & -3 & +5 & -3 \\
B1 AWR & +5 & +4 & +7 \\
B2 AWR & +8 & +4 & +7 \\
B3 AWR & +9 & +2 & +7 \\
B4 AWR & +2 & -17 & +7 \\
K2 AWR & & -1 & +7 \\
K3 AWR & & 0 & +1 \\
GPVA & 0 & &
\end{tabular}

*Values represent the error estimate assigned to each instrument based upon its performance characteristics.

The magnitudes of the errors assigned to each of the JASIN anemometers should be taken only as estimates. However, the signs of the errors and the relative magnitudes are probably correct. During the dock test, VMWR speeds were 1 to $2 \%$ lower than the Gill cup speeds, which is consistent with the belief that the Gill cups, which are fast response sensors, may overestimate the wind speed slightly and that the VMWR propellers may underestimate the wind speeds. The wind tunnel and the dock tests of the VAWR, however, showed a $6 \%$ variation between different attempts to calibrate the instrument in the wind tunnel and a nonlinear response to wind speed in the field. Thus besides the errors from the noncosine angular response and large distance constant of the VAWR cups, that instrument has an illdefined laboratory calibration that cannot be transferred to the interpretation of data from field experiments.

Generally, the performance of the JASIN anemometers during the 1978 experiment is consistent with this evaluation. Neglecting calibration errors and taking the GPVA to be a standard, the percent differences between the GPVA mean wind speed and those measured by the other instruments compare favorably to the estimates of error found by considering the performance characteristics of each sensor (Table 6). Only the K2 and K3 AWR records fail to show agreement between field performance and estimated error.

\section{Conclusions}

The JASIN wind recorder array was useful because it provided the ability to track the passage of gross features in the wind field. However, a closer examination of the wind data raised doubts about the performance of the anemometers. Using wind tunnel test results and results from literature, the performance of the JASIN wind sensors were estimated as follows: the VAWR overestimates by $10 \%$, the AWR overestimates by $7 \%$, the GPVA has the smallest error (of the order of $1 \%$ ), and the VMWR underestimates by $3 \%$. These percentages are only estimates; the sign and relative magnitude of the errors reflect differences found in the performance characteristics of the sensors and, with the exception of the K2 and K3 AWR's, are consistent with the data from the 1978 JASIN field experiment.

Given the diverse performance characteristics of the various wind recorders, the results are no worse than expected. It is difficult to make accurate wind measurements from a buoy. The very rugged, well-shielded sensors of the W2 VAWR provided the only full length wind record from a buoy. However, the value of the VAWR record is compromised by the lack of a repeatable laboratory calibration, the nonlinear performance of the sensors in the field, and the overestimation errors associated with the VAWR cups. More responsive, unshielded sensors suffered mechanical failures. Since there are also difficulties with making measurements from research ships [Augstein et al., 1974; Kidwell and Seguin, 1978] and aircraft [Telford et al., 1977], there is no absolute wind reference with which to establish the accuracy of any JASIN wind measurement (see also articles in the work of Dobson et al. [1980]). This is a serious deficiency because the possible errors are larger than the near-surface wind field variability that was to be investigated and because JASIN winds have been used to tune the latest Seasat A scatterometer wind algorithm. For the latter purpose, the W2 VAWR wind record was chosen as the JASIN standard. This buoy comparison study has shown that the performance of the W2 VAWR is difficult to understand and that it may be in error by more than was suspected by Brown et al. [1982]. They stated that it overestimates the winds by only a few tenths of a meter per second based on consistency checks with ship and buoy observations. In the future, a well-understood and calibrated reference wind measurement is needed in order to obtain the best possible ground truth of known accuracy for evaluating the scatterometer measurements of wind speed or stress.

Acknowledgments. The authors gratefully acknowledge the cooperation of the JASIN participants who made data available and who participated in discussions or provided comments on drafts of this manuscript. The deployment of the VMWR's and initial data analysis of the VMWR data were funded by the Office of Naval Research, contract N00014-74-C-0152 to Russ Davis at the Scripps Institution of Oceanography. Deployment of the $\mathrm{W}$ moorings and their instrumentation were funded by the Office of Naval Research. contract N00014-76-C-0197, NR 082-400 to Mel Briscoe at the Woods Hole Oceanographic Institution. Work done after JASIN including the preparation of this manuscript, was funded by the Office of Naval Research, contract N00014-76-C-0197, NR 083-400 (R.A.W., R.E.P.). The assistance of R. Trask, A. Ciesluk, J. Poirier, J. Dean, N. Pennington, and others is gratefully acknowledged, as is M. Lucas' typing. W.G.L. gratefully acknowledges the collaboration of S. Pond and the support of the Office of Naval Research, contract N00014-76-C-0046, NR 083-207, and of the National Research Council of Canada and the hospitality of the Institute of Oceanographic Sciences, Wormley, United Kingdom. The Deutsche Forschungsgemeinschaft, Bonn, Federal Republic of Germany, supported this work by providing F/S Meteor and the Kiel moorings $\mathrm{K} 2$ and $\mathrm{K} 3$. Contribution 5285 from the Woods Hole Oceanographic Institution.

\section{REFERENCES}

Augstein, E., H. Hober, and L. Krügermeyer, Fehler bei Temperatur- Feuchte- und Windmessungen auf Schiffen in tropischen Breiten, Meteor Forschungsergeb. Reihe B, 9, 1-10, 1974.

Bernstein, A., A note on the use of cup anemometers in wind profile experiments, J. Appl. Meteorol., 6, 280-286, 1967.

Brown, R. A., On a satellite scatterometer as an anemometer, $J$. Geophys. Res., 88, 1663-1673, 1983.

Brown, R. A., and W. T. Liu, An operational large-scale planetary boundary layer model, J. Appl. Meteorol., 21, 261-269, 1982.

Brown, R. A., V. J. Cardone, T. Guymer, J. Hawkins, J. E. Overland, W. J. Pierson, S. Peteherych, J. C. Wilkerson, P. Woiceshyn, and M. Wurtell, Surface wind analyses for Seasat, $J$. Geophys. Res., 87, 3355-3364, 1982.

Burt, W. V., A comparison of the response of identical cup anemometers mounted on a spar and a toroid buoy, J. Phys. Oceanogr., 5, 789-792, 1975.

Busch, N. E., and L. Kristensen, Cup anemometer overspeeding, $J$. Appl. Meteorol., I5, 1328-1332, 1976.

Busch, N. E., O. Christensen, L. Kristensen, L. Lading, and S. E. 
Larsen, Cups, vanes, and propeller anemometers, in Air-Sea Interaction: Instruments and Methods, edited by F. Dobson, L. Hasse, and R. Davis, 801 pp., Plenum, New York, 1980.

Businger, J. A., J. C. Wyngaard, Y. Izumi, and E. F. Bradley, Fluxprofile relationships in the atmospheric surface layer, J. Atmos. Sci., 28, 181-189, 1971.

Davis, R. E., and R. A. Weller, Propeller current sensors, in Air-Sea Interaction: Instruments and Methods, edited by F. Dobson, L. Hasse, and R. Davis, 801 pp., Plenum, New York, 1980.

Dobson, F., L. Hasse, and R. Davis (Eds.), Air-Sea Interaction: Instruments and Methods, 801 pp., Plenum, New York, 1980.

Gill, G. C., Development and use of the Gill UVW anemometer, Boundary Layer Meteorol., 3, 214-228, 1975.

Guymer, T. H., K. B. Katsaros, W. J. Shaw, P. K. Taylor, W. G. Large, and R. E. Payne, Transfer processes at the air-sea interface, Philos. Trans. R. Soc. London Ser A, 308, 250-274, 1983.

Hasse, L., M. Gruenewald, and D. E. Hasselmann, Field observations of air flow above the waves, in Turbulent Fluxes Through the Sea Surface, edited by A. Favre and K. Hasselman, 677 pp., Plenum, New York, 1977.

Hogstrom, U., A field study of the turbulent fluxes of heat, water vapour and momentum at a 'typical' agricultural site, $Q . J . R$. Meteorol. Soc., I00, 624-639, 1974.

Horst, T. W., Corrections for response errors in a three-component propeller anemometer, J. Appl. Meteorol., 12, 716-725, 1973.

Hyson, P., Cup anemometer response to fluctuating wind speeds, $J$. Appl. Meteorol., II, 843-848, 1972.

Ishida, H., Analysis of meteorological observations from an array of buoys during JASIN, M.S. thesis, Oreg. State Univ., Corvallis, 1980.

Izumi, Y., and M. L. Barad, Wind speeds as measured by cup and sonic anemometers and influenced by tower structure, J. Appl. Meteorol., 9, 851-856, 1970.

Kaganov, E. I., and A. M. Yaglom, Errors in wind-speed measurements by rotation anemometers, Boundary Layer Meteorol., 10 , $15-34,1976$.

Kidwell, K. B., and W. R. Seguin, Comparison of wind speed and direction measurements on U.S. GATE B-scale ships, NOAA Tech. Rep. EDS 28, Natl. Oceanic and Atmos. Admin., Washington, D.C., 1978.

Kondo, J., N. Gen-ichi, and Y. Fujinawa, Response of cup anemometer in turbulence, J. Meteorol. Soc. Jpn., 49, 63-74, 1971.

Large, W. G., and S. Pond, Sensible and latent heat flux measurements over the oceans, J. Phys. Oceanogr., 12, 464-482, 1982.

LeMone, M. A., The marine boundary layer, in Workshop on the Planetary Boundary Layer, 14-18 August 1978, Boulder, Colorado, edited by J. C. Wyngaard, pp. 182-246, American Meteorological Society, Boston, Mass., 1980.

MacCready, P. B., Jr., Mean wind speed measurements in turbulence, J. Appl. Meteorol., 5, 219-225, 1966.

MacCready, P. B., and H. R. Jex, Response characteristics and meteorological utilization of propeller and vane wind sensors, $J$. Appl. Meteorol., 3, 182-193, 1964.

McBean, G. A., Instrument requirements for eddy correlation measurements, J. Appl. Meteorol., 11, 1078-1084, 1972.

Onuma, K., Overestimation error of rotating type anemometers in sinusoidally fluctuating wind speed, Proc. Jpn. Natl. Congr. Appl. Mech. 7th, 269-272, 1957.

Payne, R. E., A buoy-mounted meteorological recording package, Tech. Rep. WHOI Ref. 74-40, Woods Hole Oceanogr. Inst., Woods Hole, Mass., 1974.
Payne, R. E., Performance characteristics of some wind sensors, Tech. Rep. WHOI Ref. 81-101, Woods Hole Oceanogr. Inst., Woods Hole, Mass., 1981.

Pierson, W. J., Jr., The measurement of the synoptic scale wind over the ocean, J. Geophys. Res., 88, 1683-1708, 1983.

Pollard, R. T., The Joint Air-Sea Interaction Experiment-JASIN 1978, Bull. Am. Meteorol. Soc., 59, 1310-1318, 1978.

Pollard, R. T., T. H. Guymer, and P. K. Taylor, Summary of the JASIN 1978 field experiment, Philos. Trans. R. Soc. London Ser. A, 308, 221-230, 1983

Pond, S., Some effects of buoy motion on measurements of wind speed and stress, J. Geophys. Res., 73, 507-511, 1968.

Pond, S., W. G. Large, M. Miyake, and R. W. Burling, A Gill twin propeller-vane anemometer for flux measurements during moderate and strong winds, Boundary Layer Meteorol., 16, 359-364, 1979.

Royal Society, Air-Sea Interaction Project: Summary of the 1978 Field Experiment, 139 pp. . The Royal Society, London, 1979.

SethuRaman, S., Structure of turbulence over water during high winds, J. Appl. Meteorol., 18, 324-328, 1979.

Siedler, G., and W. Zenk, JASIN 1978: Field activities on the research vessels Meteor, Planet, Poseidon, and the research aircraft D-CMET, Meteor Forschungsergeb. Reihe A, 21, 25-48, 1980.

Smith, S. D., R. J. Anderson, E. G. Banke, E. P. Jones, S. Pond, and W. G. Large, A comparison of the air-sea interaction flux measurement systems of the Bedford Institute of Oceanography and the Institute of Oceanography, University of British Columbia, Rep. Ser. BI-R-76-17, 41 pp., Bedford Inst. of Oceanogr., Vancouver, 1976.

Stewart, R. H., Estimates of the accuracy of wave measurements at JASIN, Jasin News, 21, 1-5, Oct. 1980.

Telford, J. W., P. B. Wagner, and A. Vaziri, The measurement of air motion from aircraft, J. Appl. Meteorol.. 16, 156-166, 1977.

Weller, R. A., Observations of horizontal velocity in the upper ocean made with a new vector measuring current meter, Ph.D. dissertation, Scripps Inst. of Oceanogr., La Jolla, Calif., 1978.

Weller, R. A., and R. E. Davis, A vector measuring current meter. Deep Sea Res., 27A, 565-581, 1980.

Woiceshyn, P. M., S. Peterherych, and M. G. Wurtele, SASS wind direction ambiguity removal subpanel report, Doc. 622-220, 101 pp., Jet Propul. Lab., Pasadena, Calif., 1980.

Wyngaard, J. C., J. T. Bauman, and R. A. Lynch, Cup anemometer dynamics, paper presented at Symposium on Flow: Its measurement and Control in Science and Industry, Instrum. Soc. of Am., Pittsburgh, Pa., May 9-14, 1971.

Wyngaard, J. C., J. A. Businger, J. C. Kaimal, and S. E. Larsen, Comments on "A revaluation of the Kansas mast influence on measurements of stress and cup anemometer overspeeding," Boundary Layer Meteorol., 22, 245-250, 1982.

W. G. Large, National Center for Atmospheric Research, Boulder, CO 80307.

R. A. Weller and R. E. Payne, Woods Hole Oceanographic Institution, Woods Hole, MA 02543.

W. Zenk, Institut für Meereskunde an der Universität Kiel, 2300 Kiel, Federal Republic of Germany.

(Received October 25, 1982; revised June 6, 1983; accepted June 30,1983 .) 